\title{
Firm Investment in Imperfect Capital Markets: A Structural Estimation
}

\author{
Sangeeta Pratap* \\ Centro de Investigación Económica, ITAM \\ Mexico
}

\author{
Silvio Rendón* \\ U. Carlos III and U. Pompeu Fabra \\ Spain
}

March 2002

\begin{abstract}
We set up a dynamic model of firm investment in which liquidity constraints enter explicitly into the firm's maximization problem. The optimal policy rules are incorporated into a maximum likelihood procedure to estimate the structural parameters of the model. Investment is positively related to the firm's internal financial position when the firm is relatively poor. This relationship disappears for wealthy firms, which can reach their desired level of investment. Borrowing is an increasing function of financial position for poor firms. This relationship is reversed as a firm's financial position improves, and large firms hold little debt. We find that liquidity constraints matter significantly for the investment decisions of firms. If firms can finance investment by issuing fresh equity, rather than with internal funds or debt, average capital stock is about $6 \%$ higher over a period of 20 years. Transitory interest rate shocks have a sustained impact on capital accumulation, which lasts for several periods.
\end{abstract}

Keywords: Investment, liquidity constraints, estimation of dynamic structural models, financial accelerator.

JEL Classification: C51, E22, E32, E5, G31.

* We are grateful to Mark Gertler for his constant encouragement and advice. We also thank Chris Flinn, Boyan Jovanovic, Simon Gilchrist, Ramon Marimon, Tom Sargent, Harald Uhlig and Guillaume Rabault for comments. Egon Zakrajsek gave useful advice on the data. We thank participants in seminars at the European University Institute in Florence, Hebrew University of Jerusalem, CEMFI, ITAM, SED 1999 and the Federal Reserve of Dallas for comments. We are also grateful to the editor of this journal and an anonymous referee for very useful suggestions. The responsibility for all errors is ours. Our emails: pratap@itam.mx, srendon@eco.uc3m.es. 


\section{Introduction}

A large theoretical and empirical literature has highlighted the importance of credit market frictions in understanding real activity. ${ }^{1}$ This literature rejects the MillerModigliani (1958) proposition of the irrelevance of the financial structure for real decisions, and argues that the violation of the assumptions of full information and perfect markets which underlie this proposition could create a role for a firm's net worth and its access to funds in determining investment. Asymmetric information between borrowers and lenders implies that the cost of external funds for the firm may be higher than the opportunity cost of internal funds, and related to its ability to provide collateral. This aspect of firm behavior has important consequences for the propagation of business cycles. An economic downturn that adversely affects balance sheets, and through it, a firm's collaterizable net worth, increases the agency costs of borrowing and reduces the access of firms to credit. This constrains investment and magnifies the effect of real and nominal shocks to the economy (Gertler 1988, Bernanke \& Gertler 1989, Bernanke \& Gertler 1990, Bernanke, Gertler \& Gilchrist 1999). The magnitude of these liquidity constraints and their relationship to investment is therefore a matter of some interest.

The sensitivity of investment to financial variables at the firm level has been well documented with reduced form approaches. Following Fazzari, Hubbard and Petersen (1988), this literature finds that in simple panel regressions, investment and cash flow are positively related even after investment opportunities, as measured by Tobin's $q$, are controlled for. This relationship is stronger for small firms, firms with a low dividend payout or with low bond ratings. In other words, firms which would a priori be expected to have less access to credit markets seem to display greater sensitivity of investment to internal funds. ${ }^{2}$

\footnotetext{
${ }^{1}$ For a detailed bibliography, see Bernanke, Gertler \& Gilchrist (1999).

${ }^{2}$ This result is robust across several sample splits and for several countries. Hoshi, Kashyap \& Scharfstein (1991) find that membership of an industrial keiretsu in Japan reduces the sensitivity of investment to cash flow. Similar results are obtained when the sample is divided on the basis of bond ratings (Gilchrist \& Himmelberg 1995) and size (Gertler \& Gilchrist 1994). Firm level data
} 
While such studies establish the existence of a relationship between real and financial variables at the firm level, a common criticism of their methodology is the following: in the event that $q$ is mismeasured, the cash flow variable picks up investment opportunities for firms which are not captured by $q$. The correlation between cash flow and investment could potentially arise due to this and not due to liquidity constraints. The underlying relationship between these variables is never clearly spelt out, making the coefficients on cash flow hard to interpret.

An alternative approach, which side steps the problems associated with the measurement of $q$ has been to test for the Euler condition for investment implied by a model of perfect capital markets. Most studies find that the restriction is strongly rejected for firms which have been identified as constrained. ${ }^{3}$

Although this method can circumvent the problems associated with the measurement of $q$, it suffers from some of the same drawbacks. The rejection of a null hypothesis of a specific investment model without liquidity constraints does not give us any information on what an alternative model should be. Moreover, as has been pointed out in the consumption literature (see, for example, Attanasio 1995), this method may not be able to detect liquidity constraints if their magnitude does not vary from period to period.

Our paper is an attempt to understand this relationship at a theoretical as well as an empirical level. We depart from the standard neo classical hypothesis of perfect capital markets and explicitly incorporate liquidity constraints into a dynamic model

for the U.K. (Devereaux and Schiantarelli 1989), Italy (Schiantarelli \& Sembellini 2000) and Canada (Schaller 1993) have all confirmed that constrained firms display a higher sensitivity of investment to cash flow. For a detailed review of this literature, see Hubbard (1998). An exception is Kaplan and Zingales (1997) who find that the coefficient on cash flow does not increase monotonically across groups of firms as the degree of financial constraint increases. In fact, firms which seem less constrained according to several criteria have a higher coefficient on cash flow, as compared to more constrained firms. Pratap (forthcoming) shows that this result is consistent with the presence of liquidity constraints when capital adjustment costs are non-convex.

${ }^{3}$ See for example, Whited (1992) and Kwon (1994) for this result in US firm data in the manufacturing and retail sector respectively. Similar results have been obtained for firm level data in the U.K. (Bond \& Meghir 1994) and Canada (Ng \& Schaller 1996) and aggregate data in the U.S. (Gertler, Hubbard \& Kashyap 1991). 
of firm investment. This allows us to identify the effects of financial variables on firm investment. We integrate the solution to the firm's maximization problem into a maximum likelihood procedure to estimate the structural parameters of the model. This enables us to separate the effects of real and financial variables on investment and to quantify the importance of liquidity constraints. To the best of our knowledge this is the first paper to be able to do so while circumventing the problems associated with the measurement of these variables.

The contribution of this paper is twofold. At the empirical level, estimating the structural parameters of the model and simulating time paths for investment gives us an idea of the magnitude of liquidity constraints. We are also able to trace the effects of transitory changes to cash flow. Our set up, therefore, allows us to study the effect of policy changes which affect these variables on the investment profile of firms. More generally, at a methodological level, we establish a procedure to separate the effects of firm fundamentals from those of financial variables on investment, which can then be applied to a broad class of models.

We find that the data reject a model specification of no liquidity constraints in favor of a model with some liquidity constraints. These constraints exercise a significant effect on firm investment. Their magnitude is quantified by using the parameters we estimate and simulating firm investment paths over 20 years. This path is then compared to the counterfactual investment path which would have obtained, had liquidity constraints not been imposed in the maximization problem of the firm. A comparison of the two paths shows that firms which face some degree of liquidity constraints are able to accumulate $6 \%$ less capital on average over this period as compared to firms which do not face this constraint. Moreover, a transitory increase in interest rate has a persistent effect on firm investment for the liquidity constrained group of firms. However, unconstrained firms are not affected at all by this transitory increase.

The paper is organized as follows. The next section sets out the model. While a closed form solution does not exist, we characterize the optimal policy rules for 
capital and debt, and present some numerical simulations to illustrate the intuition behind the model. Section 3 discusses the data used in the estimation. In Section 4, we discuss the sources of identification, the estimation procedure and the construction of the likelihood function. We also discuss the results we obtain. Section 5 compares the model predicted distributions of capital stock and debt with the actual data and shows the results of goodness of fit tests. In section 6 , we present the results of policy experiments using the parameters we estimated. Section 7 concludes.

\section{The Model}

The model we use is a simple neo classical model of investment, augmented by liquidity constraints and an exit rule for firms. Firms maximize the expected sum of a discounted stream of dividends by choosing investment and debt each period. Liquidity constraints enter the problem in the following ways: (i) the firm is restricted in the amount of equity it can issue, ${ }^{4}$ (ii) if the value of the firm falls below its outside option, it defaults on its debt and leaves the industry, (iii) debt is available at a rate which takes this possibility of default into account and is higher than the risk free rate. $^{5}$

We depart from the conventional neoclassical investment model in that we do not include convex adjustment costs of capital. Recent literature has highlighted the role of irreversibilities and non convexities in adjustment costs and indicated that there may be no empirical basis for the commonly used quadratic functional form. ${ }^{6}$ It is

\footnotetext{
${ }^{4}$ We motivate this assumption by the fact that equity finance is expensive for firms as external investors do not know about firm quality and demand a premium on their return (Greenwald, Stiglitz \& Weiss 1984, Myers \& Majluf 1984). Gomes (2001) posits an exogenous parameterized cost of external funds, in a model where new equity is the only source of external finance. Cooley and Quadrini (2001) also use an exogeneous parameter for equity costs. For a model which endogenizes firms' initial public offering see Clementi (2000).

${ }^{5}$ Gross (1994) has a model with a similar exit rule but a different debt contract and equity restriction.

${ }^{6}$ See for example Doms \& Dunne (1998), Ito (1996), Barnett \& Sakelleris (1998) and Abel \& Eberly (1995).
} 
beyond the scope of this paper to establish an appropriate specification of adjustment costs and therefore we do not address this issue. ${ }^{7}$

It is worth mentioning here that, like Cooley \& Quadrini (2001) we use simple one period debt contracts. The equity constraint and the exit rule are imposed exogenously to make the estimation of the model possible, and the borrowing constraint arises endogenously as a result of the latter. There is a large literature which studies endogenous borrowing constraints as a consequence of asymmetric information or enforceability restrictions. See for example, Kocherlakota (1996), Alburquerque and Hopenhayn (1997), Kehoe and Levine (1993) and Cooley, Marimon and Quadrini (2000). While such an approach is certainly more theoretically complete, the mapping from these models to the data is by no means clear and this is a constraint for estimating them. Furthermore, embedding an optimal contract in our framework significantly increases the computational burden. Nevertheless, as the next section shows us, this relatively simple model is also able to account for several of the stylized facts that other models can. We therefore leave the question of estimating models with enforceability and information restrictions for future research.

\subsection{The firm's problem}

The firm chooses investment and borrowing to maximize its objective function, which is defined as:

$$
\max _{I, B^{\prime}} E_{0} \sum_{t=0}^{\infty}\left(\frac{1}{1+\rho}\right)^{t} D_{t}
$$

\footnotetext{
${ }^{7}$ In other work (Pratap forthcoming, Rendón 1999) we consider the interaction between liquidity constraints and non convex adjustment costs.
} 
where $\rho$ is the discount rate (assumed to be equal to the risk free rate). $D$ represents the firm's dividends ${ }^{8}$ at time $t$, which are defined as

$$
D=\theta K^{\alpha}-(1+r) B-I+B^{\prime}
$$

$B$ is the firm's debt that must be paid at time $t$, at the interest rate $r, I$ is the firm's investment at time $t$, and $B^{\prime}$ is the debt contracted at period $t$, that will be due in the next period $t+1$. Capital accumulation satisfies the law of motion

$$
K^{\prime}=(1-\delta) K+I
$$

where $K$ and $K^{\prime}$ are the capital stock at time $t$ and $t+1$ respectively, and $\delta$ denotes the depreciation rate which is assumed to be the same for all firms and constant over time.

The firm operates in a risky environment captured by an idiosyncratic productivity $\theta$, which follows a Markov process $P\left(\theta^{\prime} \mid \theta\right)$, parameterized as an $\mathrm{AR}(1)$ process, $\theta^{\prime}=\gamma \theta+\varepsilon, \varepsilon \sim N\left(\mu, \sigma^{2}\right)$. This variable can be a technology or demand shock and is observed by the firm and the lenders before investment and borrowing decisions are made.

In what follows, we shall find it convenient to define the firms' financial resources $x$ as the sum of profits and undepreciated capital, net of debt repayments, i.e.

$$
x=\theta K^{\alpha}+(1-\delta) K-(1+r) B
$$

Liquidity constraints enter the firms problem in the following way. The restriction on issuing equity implies

$$
D \geq \bar{D}
$$

\footnotetext{
${ }^{8}$ Since we are going to estimate the model, it is convenient to introduce functional forms right away.
} 
A particular case of this constraint is that dividends are non negative, i.e., $D \geq 0$.

Let the interest rate charged on debt $B^{\prime}$ be $r^{\prime}$. Assuming that lenders have access to an elastic supply of funds at the risk free rate, competition among lenders leads to a zero expected profit condition which pins down interest rates in the following way:

$$
G\left(r^{\prime}\right)=(1-\pi)\left(1+r^{\prime}\right) B^{\prime}-(1+\rho) B^{\prime}=0
$$

where $\pi$ is the probability of exit which will be derived subsequently. The first term represents the expected return of the lender while the second term is the opportunity cost of the funds. The interest rate emerging from this condition is $r^{\prime}\left(K^{\prime}, B^{\prime}, \theta\right)$ and is explained below in greater detail.

We also rule out that the firm lends money in any way, by assuming that borrowing is strictly non negative, that is

$$
B^{\prime} \geq 0
$$

The sequence of events is as follows: a firm enters each period with a stock of capital $K$ and a stock of debt $B$; the latter is contracted at an interest rate $r$. The stochastic shock $\theta$ is realized which determines the value of $x$. If $x<0$, the firm defaults on its debt and exits. A non negative $x$ implies that the firm pays its debts and continues. We abstract from enforceability problems and assume that firms will always pay their debts if they are able. A continuing firm chooses its capital stock and debt for the next period, $K^{\prime}$ and $B^{\prime}$, subject to the constraints described above. These also determine the interest rate, $r^{\prime}$ at which $B^{\prime}$ is contracted. We can therefore 
write the firms' problem in recursive form as follows,

$$
\begin{aligned}
V\left(K, B, \theta, \theta_{-1}\right)= & \max \left[\operatorname { m a x } _ { K ^ { \prime } , B ^ { \prime } } \left\{\theta K^{\alpha}+(1-\delta) K-\left(1+r\left(K, B, \theta_{-1}\right)\right) B-K^{\prime}+B^{\prime}\right.\right. \\
& \left.\left.+\frac{1}{1+\rho} \int V\left(K^{\prime}, B^{\prime}, \theta^{\prime}, r^{\prime}\left(K^{\prime}, B^{\prime}, \theta\right)\right) d P\left(\theta^{\prime} \mid \theta\right)\right\}, \Omega(\theta)\right] \\
& \text { subject to }(1), \text { and }(2),
\end{aligned}
$$

where $\theta_{-1}$ represents the value of the productivity shock in the previous period and $\Omega(\theta)$ represents the value of the outside option. Alternatively, since $\theta$ (and therefore the value of $x$ ) is realized before the investment and borrowing decisions are made, we can rewrite the state variables as $x$ and $\theta$. The value function can therefore be expressed as

$$
\begin{aligned}
\widehat{V}(x, \theta)= & \max \left[\max _{K^{\prime}, B^{\prime}}\left\{x-K^{\prime}+B^{\prime}+\frac{1}{1+\rho} \int \widehat{V}\left(x^{\prime}, \theta^{\prime}\right) d P\left(\theta^{\prime} \mid \theta\right)\right\}, \Omega(\theta)\right] \\
& \text { subject to (1) and (2) }
\end{aligned}
$$

where $\widehat{V}\left(\theta K^{\alpha}+(1-\delta) K-\left(1+r\left(K, B, \theta_{-1}\right)\right) B, \theta\right)=V\left(K, B, \theta, \theta_{-1}\right)$.

We now characterize the value of the outside option $\Omega(\theta)$ and the debt contract in more detail. One possibility is to normalize $\Omega(\theta)=0$, which implies that the firm will stay in the industry until the value of continuing is zero. Another possibility is to allow for transferability of the firm's idiosyncratic productivity to another activity. Here we assume that the firm follows the latter course and $\Omega(\theta)=\widehat{V}(0, \theta)$. In other words, the firm will exit when it is unable to pay its current liabilities (since debt is one period, all liabilities are current) out of its existing assets, namely the value of production and capital stock. In this event, the firm defaults on its debt. ${ }^{9}$ Define $\underline{\theta}$

\footnotetext{
${ }^{9}$ We rule out the possibility of the firm defaulting and staying in the same business, an event that we do not observe in our data. The value of production and undepreciated capital in this situation goes to pay bankruptcy costs and cannot be appropriated by the lender or by the firm. The value of $\Omega(\theta)$ can be non negative because the firm is able to transfer its productivity to other activities.
} 
as the value of $\theta$ at which $x=0$ i.e.

$$
\underline{\theta}^{\prime}=\left(1+r^{\prime}\right) B^{\prime} K^{\prime-\alpha}-(1-\delta) K^{\prime-\alpha}
$$

Then the exit rule implies that

$$
\begin{array}{ll}
\text { if } \theta^{\prime} \geq \underline{\theta}^{\prime}, & \text { the firm stays; } \\
\text { if } \theta^{\prime}<\underline{\theta}^{\prime} & \text { the firm exits. }
\end{array}
$$

The probability of survival can be therefore expressed by $\pi=\operatorname{Pr}\left(\theta^{\prime}>\underline{\theta}^{\prime} \mid \theta\right)=1-\Phi\left(\kappa^{\prime}\right)$, where $\kappa^{\prime}=\left(\frac{\underline{\theta}^{\prime}-\gamma \theta-\mu}{\sigma}\right)$ and $\Phi($.$) is the area under the standard normal curve. Since$

$$
\begin{aligned}
& \underline{\theta}_{K^{\prime}}^{\prime}=-\left(1+r^{\prime}\right) \alpha K^{\prime-\alpha-1} B^{\prime}-(1-\delta)(1-\alpha) K^{\prime-\alpha}<0, \text { and } \\
& \underline{\theta}_{B^{\prime}}^{\prime}=\left(1+r^{\prime}\right) K^{\prime-\alpha}>0
\end{aligned}
$$

the survival probability at time $t^{\prime}$, conditional on surviving the previous period is positively related to the amount of capital the firm has at this time $K^{\prime}$, and is inversely related to its debt liabilities $B^{\prime}$. We can therefore think of the exit rule as a Chapter 7 bankruptcy, where a firm declares bankruptcy when it cannot meet its debt obligations, and is allowed to keep "the tools of its trade". ${ }^{10}$

This implies that the interest rate is firm-specific and is defined as

$$
r^{\prime}\left(K^{\prime}, B^{\prime}, \theta\right)=\left\{r^{\prime} \mid G\left(r^{\prime}\right)=0\right\}
$$

If survival were guaranteed, i.e. $\Phi\left(\kappa^{\prime}\right)=0, r^{\prime}=\rho$. On the other hand, firms with zero survival probability $\left(\Phi\left(\kappa^{\prime}\right)=1\right)$ face an infinitely high rate of interest. The derivatives of the interest rate over capital and debt are obtained using the implicit function theorem. They are $r_{K^{\prime}}^{\prime}=\underline{\theta}_{K^{\prime}}^{\prime} B^{\prime} K^{\prime \alpha} \Upsilon<0$, and $r_{B^{\prime}}^{\prime}=\underline{\theta}_{B^{\prime}}^{\prime} B^{\prime} K^{\prime \alpha} \Upsilon>0$, where

\footnotetext{
${ }^{10}$ See Eraslan (2000) for a model of Chapter 11 bankruptcy where creditors negotiate the reorganization of a firm after it is cannot meet its liabilities.
} 
$\Upsilon=\frac{\lambda\left(\kappa^{\prime}\right) B^{\prime} K^{\prime \alpha}\left(1+r^{\prime}\right)}{1-\lambda\left(\kappa^{\prime}\right) B^{\prime} K^{\prime \alpha}\left(1+r^{\prime}\right)} \geq 0$, and $\lambda\left(\kappa^{\prime}\right)=\frac{\frac{1}{\sigma} \phi\left(\kappa^{\prime}\right)}{1-\Phi\left(\kappa^{\prime}\right)}>0$ is the inverse Mills's ratio, which is positive as truncation occurs from below. It is also clear that if $K^{\prime} \geq B^{\prime}$, then $r_{K^{\prime}}^{\prime}+r_{B^{\prime}}^{\prime}>0$.

The interest rate is therefore decreasing in capital and increasing in debt. The intuition behind this result is very simple. More capital tomorrow will increase the firms' value and reduce the value of the outside option. Similarly, a larger amount of debt will, other things equal, lower the probability of survival. Equation (3) therefore gives us a supply schedule of debt faced by a firm. More details can be found in Appendix A.1.

\subsection{Optimal Policy}

To solve this problem, we form the Lagrange equation, which becomes the new maximand:

$$
\begin{aligned}
L\left(K^{\prime}, B^{\prime}, \xi, \zeta\right)= & \max _{K^{\prime}, B^{\prime}, \xi, \zeta} x-K^{\prime}+B^{\prime}+\frac{1}{1+\rho} \int V\left(K^{\prime}, B^{\prime}, \theta^{\prime}, \theta\right) d P\left(\theta^{\prime} \mid \theta\right) \\
& +\xi\left(x-K^{\prime}+B^{\prime}-\bar{D}\right)+\zeta B^{\prime} .
\end{aligned}
$$

The first order conditions for this problem are then

$$
\begin{aligned}
L_{K^{\prime}} & =-1+\frac{1}{1+\rho}\left(\widetilde{E} V_{1}+r_{K^{\prime}}^{\prime} \widetilde{E} V_{4}\right)-\xi=0, \\
L_{B^{\prime}} & =1+\frac{1}{1+\rho}\left(\widetilde{E} V_{2}+r_{B^{\prime}}^{\prime} \widetilde{E} V_{4}\right)+\xi+\zeta=0, \\
L_{\xi} & =x-K^{\prime}+B^{\prime}-\bar{D}=0, \\
L_{\zeta} & =B^{\prime}=0,
\end{aligned}
$$


where $\widetilde{E} V_{j}=\int_{\theta^{\prime}>\underline{\theta^{\prime}}} V_{j} d P\left(\theta^{\prime} \mid \theta\right), j=\{1,2,4\}$. Their explicit expressions are:

$$
\begin{aligned}
\widetilde{E} V_{1}^{\prime} & =\int_{\theta^{\prime}>\underline{\theta}^{\prime}}\left(\alpha \theta^{\prime} K^{\prime \alpha-1}+(1-\delta)\right)\left(1+\xi^{\prime}\right) d P\left(\theta^{\prime} \mid \theta\right), \\
& =\alpha\left(\gamma \theta+\mu+\sigma \lambda\left(\kappa^{\prime}\right)+\widetilde{E}\left(\theta^{\prime} \xi^{\prime}\right)\right) K^{\prime \alpha-1}+(1-\delta)\left(1-\Phi\left(\kappa^{\prime}\right)+\widetilde{E} \xi^{\prime}\right), \\
\widetilde{E} V_{2}^{\prime} & =-\left(1+r^{\prime}\right) \int_{\theta^{\prime}>\underline{\theta}^{\prime}}\left(1+\xi^{\prime}\right) d P\left(\theta^{\prime} \mid \theta\right)=-\left(1+r^{\prime}\right)\left(1-\Phi\left(\kappa^{\prime}\right)+\widetilde{E} \xi^{\prime}\right), \\
\widetilde{E} V_{4}^{\prime} & =-B^{\prime} \int_{\theta^{\prime}>\underline{\theta}^{\prime}}\left(1+\xi^{\prime}\right) P\left(\theta^{\prime} \mid \theta\right)=-B^{\prime}\left(1-\Phi\left(\kappa^{\prime}\right)+\widetilde{E} \xi^{\prime}\right) .
\end{aligned}
$$

Proposition $1 \zeta \neq 0 \rightarrow \xi=0$ Proof: In Appendix A.1.

This proposition asserts that a firm cannot simultaneously incur debt and issue positive dividends. The intuition for this result is simple. If a firm borrows a dollar to pay out as dividends, the cost it incurs is $\frac{1+r}{1+\rho} \geq 1$, whereas the benefit is 1 . Hence a firm will only borrow if the marginal benefit is greater than the marginal cost, which is only the case when the debt is used to finance capital stock. Proposition 1 implies that there can be three possible regimes which can be summarized as follows

\begin{tabular}{cccc}
\hline \hline & Regime I & Regime II & Regime III \\
\hline$\xi$ & $\xi>0$ & $\xi>0$ & $\xi=0$ \\
$\zeta$ & $\zeta=0$ & $\zeta>0$ & $\zeta>0$ \\
$x$ & $x<K^{*}(\theta)+\bar{D}$ & $K^{* *}(\theta) \leq x-\bar{D}<K^{* * *}(\theta)$ & $x \geq K^{* * *}(\theta)+\bar{D}$ \\
$K^{\prime}(x, \theta)$ & $K^{*}(x, \theta)$ & $x-\bar{D}$ & $K^{* * *}(\theta)$ \\
$K_{x}^{\prime}$ & $>0$ & 1 & 0 \\
$B^{\prime}(x, \theta)$ & $K^{*}(x, \theta)-x+\bar{D}$ & 0 & 0 \\
$B_{x}^{\prime}$ & $K_{x}^{\prime}-1$ & 0 & 0 \\
\hline
\end{tabular}


where capital is defined implicitly by the formulae:

$$
\begin{aligned}
K^{*}(x, \theta) & =\left\{K^{\prime} \mid B^{\prime}=K^{\prime}-x+\bar{D}, \widetilde{E} V_{1}+\widetilde{E} V_{2}=-\left(r_{K^{\prime}}^{\prime}+r_{B^{\prime}}^{\prime}\right) \widetilde{E} V_{4}\right\}, \\
K^{* *}(\theta) & =\left\{K^{\prime} \mid \widetilde{E} V_{1}+\widetilde{E} V_{2}=0\right\}, \\
K^{* * *}(\theta) & =\left\{K^{\prime} \mid \widetilde{E} V_{1}=(1+\rho)\right\} .
\end{aligned}
$$

The optimal solution for capital can be also written as

$$
K^{\prime}(x, \theta)=\min \left(\max \left(K^{*}(x, \theta), x-\bar{D},\right) K^{* * *}(\theta)\right)
$$

In Appendix A.3. we show that capital is increasing in $x$ in regime I. In all three regimes the optimal solution for debt is

$$
B^{\prime}(x, \theta)=\max \left(K^{\prime}(x, \theta)-x+\bar{D}, 0\right)
$$

Notice that under all regimes and dividend constraints $K^{\prime} \geq B^{\prime}$, which implies $r_{K^{\prime}}^{\prime}+$ $r_{B^{\prime}}^{\prime}>0$.

The three regimes can be described as follows: In the first regime, firms have relatively low financial resources and contract debt. By proposition 1 we know that a firm will never borrow to pay out dividends, hence it must be accumulating capital. It is also hitting the lower limit on dividends. The slope of $K^{\prime}$ with respect to $x$ is therefore positive and greater than 1 when debt is increasing and less than 1 when debt is decreasing. In regime II, the firm is able to accumulate capital completely out of its own internal resources and will therefore not borrow. It could however issue equity if $\bar{D}<0$. In this case, the firm is spending its entire internal resources on capital accumulation and the slope of $K^{\prime}$ with respect to $x$ is 1 . The dividend constraint is binding. In regime III, the firm has reached the steady state of capital. Notice that the capital stock in this case depends only on the parameters of the model and is not a function of $x$. In this case, further increases in $x$ will not induce the firm 
to increase its capital stock. It will also issue dividends if $x>K^{* * *}(\theta)$.

To illustrate some properties of the model, we present simulations of the policy rules. $^{11}$ Figure 1 and 2 present cross sections of the policy functions for $K^{\prime}$ and $B^{\prime}$ as a function of $x$ for different values of $\theta$. For a given value of $\theta$, the firms' capital stock is positively related to $x$ for firms with low $x$ (regime I and II). For high $x$, in regime III, where the dividend constraint is not binding, the policy function is a horizontal line, i e. $K^{\prime}$ is not sensitive to $x{ }^{12}$ Higher values of $\theta$, which improve the profitability of the firm, shifts this policy function upwards.

Similarly, the policy rule for debt shows an inverted U shape. In this model, debt is a double-edged sword. For a given productivity, firms need to borrow to invest and this increases their expected profits. On the other hand, it also leaves them more vulnerable to bad shocks and increases the probability of exit. The policy function of debt reflects these two opposing tendencies. Initially increases in $x$, by allowing firms to increase their capital stock, also lower the interest rate. This allows the firm to borrow and to accumulate capital, and $x$ and $B^{\prime}$ display the positive relationship we observe. However as a firm grows wealthier, its need to borrow to accumulate capital becomes smaller and is outweighed by the risks of default. $B^{\prime}$ declines, creating the inverted $U$ shape that we observe. Higher values of $\theta$ reduce the prospect of future bankruptcy, allowing the firm to borrow larger amounts and shift the policy rule up.

\footnotetext{
${ }^{11}$ The parameter values used in this simulation are $\alpha=0.6, \rho=0.02, \delta=0.12, \gamma=0.8, \mu=0.5$, $\sigma=1.05 . \bar{D}$ is assumed to be 0 . The numerical solution is computed for assigned parameter values by discretizing the state space (all possible combinations of $K$ and $B$ and $\theta$ ) into a grid of points. This gives us a discrete state space for $x$ as well. Starting with an arbitrary initial magnitude for $V_{0}$, the value function is maximized with respect to $K$ and $B$, subject to the constraints mentioned above, to get the policy functions for capital and debt associated with $V_{0}$. Using these policy functions, a new value function is computed. The expectation of the value function is computed by discretizing the probability distribution of $\theta$ and integrating it over all permissible values of $\theta$. This process is repeated until the value function converges. Further details of the discretization and the solution technique are given in Appendix B.

${ }^{12}$ Note that there is no reason for the policy function to start at zero, i.e. $K^{\prime}(0, \theta)$ and $B^{\prime}(0, \theta)$ can be greater than zero for a sufficiently high level of $\theta$.
} 
The slope of the policy function can be represented as

$$
\frac{\partial \widehat{V}}{\partial x}=1+\xi+\zeta=(1+\Upsilon)\left(1+\frac{\widetilde{E} \xi^{\prime}}{\left(1-\Phi\left(\kappa^{\prime}\right)\right)}\right)>1
$$

For a firm which has either of the constraints binding, this slope is clearly greater than 1. In particular, $\Upsilon$ is positive if $B>0$, that is, in regime I. In regimes II and III also, $\frac{\partial \widehat{V}}{\partial x}>1$, that is, even in parts of regime III, the firm is constrained, because of the expectation of hitting the dividend constraint next period. It is decreasing in $x$, as shown in Figure 3. For a liquidity constrained firm, given a level of productivity $\theta$, an increment to $x$ represents not only an increase in wealth, but also an opportunity to increase its capital stock. Firms which are closer to their desired level of capital place a lower value on $x$, as shown by the declining slope. When liquidity constraints are not binding the slope of the value function approaches 1 . At this point, the value of an additional unit of resources within the firm is the same as the value of a unit of resources outside the firm. Higher values of $\theta$ shift the curve out since an additional unit of capital obtained by investing $x$ is more productive, thus giving the firm a higher value.

The dividends of the firm can be written as

$$
D=\max \left(x-K^{* * *}, \bar{D}\right) .
$$

In this particular example, we have parametrized $\bar{D}$ to be zero. Hence, as Figure 4 illustrates, firms with low $x$ which are not at their desired level of capital do not pay any dividends. Only firms with high financial resources that reach their desired level capital will issue dividends.

We therefore see that this model delivers results which are consistent with several stylized facts of firm investment and financial behavior. If we are willing to identify "small firms" with low $x$ firms, we see that small firms pay fewer dividends, invest more, and take on more debt (Fazzari, Hubbard and Petersen 1988, Hall and Hall 
1993). They also have a higher probability of exit (Evans 1987, Hall 1987). Investment of small firms is also more sensitive to changes in cash flow, while this relation is weaker for large firms.(See for example, Fazzari, Hubbard and Petersen 1988, Gilchrist and Himmelberg 1994, 1998).

\subsection{The dividend constraint}

Equation (4) can be also formulated as

$$
K^{* * *}(\theta)=\left\{K^{\prime} \mid K^{\prime}=\left(\frac{\alpha\left(\gamma \theta+\mu+\sigma \lambda\left(\kappa^{\prime}\right)+\widetilde{E}\left(\theta^{\prime} \xi^{\prime}\right)\right)}{1+\rho-(1-\delta)\left(1-\Phi\left(\kappa^{\prime}\right)+\widetilde{E} \xi^{\prime}\right)}\right)^{\frac{1}{1-\alpha}}\right\}
$$

If there were no dividend constraint, we would not have the three regimes, but just one with $\xi=0$ at all times, that is, with $\widetilde{E} \xi^{\prime}=0$ and $\widetilde{E}\left(\theta^{\prime} \xi^{\prime}\right)=0$.

$$
K_{n d}^{\prime}(\theta)=\left\{K^{\prime} \mid K^{\prime}=\left(\frac{\alpha\left(\gamma \theta+\mu+\sigma \lambda\left(\kappa^{\prime}\right)\right)}{(1+\rho)-(1-\delta)\left(1-\Phi\left(\kappa^{\prime}\right)\right)}\right)^{\frac{1}{1-\alpha}}\right\}
$$

We have an implicit definition of capital that only depends on parameters and on a predetermined productivity $\theta$. The dividend constraint that mimics this result is $\widetilde{D}(\theta)=-K_{n d}^{\prime}(\theta)$. At this point a firm can always attain its optimal level of capital stock, even if $x=0 .{ }^{13}$ Any constraint $\bar{D}(\theta) \leq \widetilde{D}(\theta)$ will be redundant; hence, a constraint will only bind if $\bar{D}(\theta)>\widetilde{D}(\theta)$. Let $\bar{D}(\theta)=s \widetilde{D}(\theta), s \in[0,1]$ is then a measure of the tightness of the dividend constraint.

Proposition 2 (i) If $s \geq 1$, then $K^{* * *}(\theta)=K_{n d}(\theta)$. (ii) If $s<1$, then $K^{* * *}(\theta)>$ $s K_{n d}(\theta)$. Proof: In Appendix A.2.

Notice that the sign of $K^{* * *}(\theta)-K_{n d}(\theta)$ is ambiguous as the sign of $\widetilde{E}\left(\theta^{\prime} \xi^{\prime}\right)$ is ambiguous in spite of $\widetilde{E} \xi^{\prime}>0$. The fear of a binding constraint in the future may

\footnotetext{
${ }^{13}$ Notice that allowing firms to borrow as much as they wish at the risk free rate would not mimic this result because of the exit rule. Fear of bankruptcy would precent firms from borrowing large amounts to reach this value of capital.
} 
induce an overaccumulation of capital in the current period.

Proposition 3 If $s \geq(<) 1$, then $B^{\prime}(x, \theta)=(\geq) 0, K_{x}^{\prime}=(\geq) 0, B_{x}^{\prime}=(\gtreqless) 0$.

Proof: In Appendix A.2.

Without liquidity constraints $(s \geq 1)$ two firms with the same productivity level but different financial position have the same expected path of future state variables. The firm with the lower $x$ will be able to make up the shortfall by issuing as much equity as it needs, without incurring in debt and without capital stock being sensitive to $x$. With liquidity constraints $(s<1)$ these two firms will have different expected paths. This is the basis of our identification of liquidity constraints in Subsection 4.1.

Figures 5 and 6 show the policy rules for capital and debt according to the tightness of the dividend constraint. For $s=0.5$, we see that the effect of the constraint is not identical for all firms. Smaller firms are able to accumulate more, and than in the case of $s=0$. On the other hand, the steady state value of capital is lower with $s=0.5$, suggesting that when $s=0$, firms also have a precautionary motive in accumulating capital. Debt is always lower in this case since firms have another costless source of funds.

It is worth noting that this formulation of liquidity constraints assumes a very special structure of the costs of issuing equity. If dividends are negative but greater than $\bar{D}(\theta)$, this implies that the firm is able to issue equity (negative dividends) costlessly. On the other hand, issuing equity beyond $\bar{D}(\theta)$ has an infinite cost. Another possibility is to assume an exogenous cost structure for equity as in Gomes (2001). However, from an estimation point of view the parameters of this function would not be identified with our data. We therefore choose to go with this approach.

\section{Data}

The data used in this estimation are from the Standard \& Poor Industrial Compustat database and cover the period 1976 to 1995. Since our model does not admit any 
heterogeneity, other than the firm specific shock, we try to reduce systematic differences between firms by using data from a single 2 digit industry group. Our dataset consists of a sample of 89 firms from the fabricated metals, machinery and transport equipment sector (SIC 34). This is not a balanced panel and we have many missing observations. The data used and their definitions from Compustat are

Investment $(I)$ : $\quad$ Capital Expenditure on Property , Plant and Equipment;

Capital Stock $(B K)$ : Beginning Balance of the Year's Capital Stock (Book Value); Borrowing $(B)$ : Debt in Current Liabilities.

The frequency of the data is yearly and all quantities are in millions of dollars. A firm is included in the sample if it has data on investment and debt continuously for ten or more years. Firms which report zero capital stock for one or more years in the sample period are not included. The replacement value of capital stock is constructed using the perpetual inventory method, using the first observed book value of capital stock to initialize the series. Firms for which this initial observation of capital stock is missing are excluded from the sample. We also remove outliers following a method used by Gilchrist \& Himmelberg (1995). Further details of sample selection and construction of the replacement value of capital stock are given in Appendix C.

[Table 1 about here]

Average investment, borrowing and capital stock of the pooled data are given in Table 1. Firms have a mean yearly investment of roughly $\$ 17$ million, and debt of $\$ 13$ million. $K_{t}$ refers to the book value of capital stock for each firm in the first year that it is observed. This initial average is about $\$ 100$ million. However, the data are widely dispersed, i.e. the standard deviations (especially for capital stock) are all large.

We also carried out some reduced form estimations ${ }^{14}$ which show that the dy-

\footnotetext{
${ }^{14}$ The results of these estimations are available on request from the authors.
} 
namic model predicted relationships between capital and debt are borne out in the data. These estimations are of course not sufficient to quantify the magnitude of the liquidity constraints.

\section{Estimation}

We now turn to the estimation to recover the parameters of the structural model. We use the policy rules obtained from the solution of the dynamic programming problem as inputs into the computation of a likelihood function. The estimation consists of finding the parameters which maximize the probability of observing the data, given the structural model.

\subsection{Identification}

The basic source of identification of the seven structural parameters of the model is the individual firm's evolution of capital and debt. In particular, the debt data are crucial for identifying those parameters that are not part of the stochastic process, namely $\alpha, \delta, \rho, s$.

If there is no dividend constraint, that is, $s \geq 1$, we can directly assume that $s=1$, as any $s>1$ produces exactly the same policy rule as $s=1$, as explained above. In this case debt must be zero at all times and capital is given by equation (6). In this implicit equation $\alpha, \delta, \rho$ are identified by its functional form. If firms did not exit, it is easy to see that $\alpha, \delta$, and $\rho$ are not identified as optimal capital would be $K_{n d}=\left(\frac{\alpha(\gamma \theta+\mu)}{\rho+\delta}\right)^{\frac{1}{1-\alpha}}$. Consequently, to guarantee identification, we do not estimate $\alpha, \delta$, and $\rho$ if $s=1$.

If $s$ is estimated, that is, if $0 \leq s \leq 1$, we also constrain $\alpha, \delta$, and $\rho$. That way $s=1$ is identified and becomes also an admissible value for an estimate. As stated in Proposition $3, s<1$ implies that $B^{\prime}>0$ in regime I, and $B^{\prime}=0$ in regimes II and III. 
Thus, in regime I debt is defined by

$$
B^{\prime}=K^{\prime}-\theta K^{\alpha}-(1-\delta) K+(1+\rho) \frac{B}{1-\Phi(\kappa)}-s K_{n d}
$$

where capital $K^{\prime}$ is defined in equation (5). Since we are fixing $\alpha, \delta$, and $\rho$, from these two equations we can identify the parameters of the stochastic process, $\gamma, \mu, \sigma$, and with them, we can determine $K_{n d}$. The tightness of the dividend constraint $s$ is then recovered from the debt equation. In regimes II and III, $B^{\prime}=0$, so the dividend constraint implies $K^{\prime} \leq \theta K^{\alpha}+(1-\delta) K-(1+\rho) \frac{B}{1-\Phi(\kappa)}+s K_{n d}$.In regime II this condition holds with equality, so identification of $s$ is similar as in regime I. In regime III this condition holds with strict inequality, which gives an upper threshold for an admissible level of capital. Consequently, identification of $s$ comes primarily from regime I and II, that is, when the dividend constraint is binding.

If $s=0$, identification is similar as in the previous cases; however, the debt equation and equation (5) allow us to additionally identify $\alpha, \delta, \rho$ and the parameters of the stochastic process of productivity.

We perform several estimations for different levels of tightness of the dividend constraint. We estimate $\alpha, \delta, \rho$ in the specification $s=0$, and take them as given in the other specifications to estimate the remaining parameters. We check for robustness by reestimating the model with values of $\alpha, \delta, \rho$ that are commonly used in calibration exercises.

Since some specifications of the model, like $s=1$, imply zero debt at all times, to avoid zero probability events we include measurement error in debt at all periods. As we do not observe initial productivity, we try to infer its value from the first observation of capital and debt. For that we need to add measurement error in initial capital. We further test for the impact of this error by reestimating the model with a restricted variance on the measurement error of capital. 


\subsection{Log-Likelihood function}

The log-likelihood function is the sum of the log of each firm's joint density of the observed investment and debt, conditional on the first observation.

$$
\ln \mathcal{L}=\sum_{i=1}^{N} \ln f_{i T}\left(\left\{I_{i, t-1}^{o b s}, B_{i t}^{o b s}\right\}_{t=2}^{T} \mid K_{i 1}^{o b s}, B_{i 1}^{o b s}\right) .
$$

This multivariate density can be split into the product of conditional densities. We can construct a likelihood function for the whole evolution of observables, integrating out the unobservable productivity shock. In our case, the observables and unobservables are serially correlated, which complicates the construction of the likelihood function by requiring several integrations.

For the first observation we know the levels of capital and debt, $K_{1}^{\text {obs }}, B_{1}^{\text {obs }}$, but we do not know the associated productivity level $\theta_{1}$, nor do we know $r$ or $\theta_{0}$ (to improve legibility, we omit subscripts for individual firms). However, using the policy rules $K(x, \theta)$ and $B(x, \theta)$ we can determine the density for a certain $\theta_{0}$ in the previous period given $K_{1}$ and $B_{1}$. A complication in inverting these policy rules is that the same capital and debt can be the result of several different combinations of $x$ and $\theta .{ }^{15}$ In case of multiple solutions we assume that each of these combinations is equally likely. We first build the indicator function

$$
\begin{aligned}
I\left(K_{1}, B_{1} \mid x_{0}, \theta_{0}\right) & =1, \text { if } K_{1}=K^{\prime}\left(x_{0}, \theta_{0}\right) \text { and } B_{1}=B^{\prime}\left(x_{0}, \theta_{0}\right) \\
& =0, \text { otherwise. }
\end{aligned}
$$

The density for the productivity level, conditional on capital and debt in the first

\footnotetext{
${ }^{15}$ This is because of the flat portion of the policy rule in regime III. Additionally, the discretization of the state space can collapse two originallly different levels of capital or of debt into the same discretized level.
} 
period is given by

$$
w\left(\theta_{0} \mid K_{1}, B_{1}\right)=\frac{\int I\left(K_{1}, B_{1} \mid x, \theta_{0}\right) d x}{\iint I\left(K_{1}, B_{1} \mid x, \theta\right) d x d \theta}
$$

that is, the set of all values of $\theta_{0}$ that produce the combination $K_{1}, B_{1}$ divided over all possible combinations of $x, \theta$ that produce $K_{1}, B_{1}$. Appendix $\mathrm{D}$ describes the discretized version of this inversion, which is the one used in the actual computation. To facilitate the computation of this inverse we introduce (normally distributed) classical measurement error in the first observation of capital. As mentioned above, to avoid collapse of the likelihood function when $s$ is close to zero, we also add measurement error in debt at all times. Hence the observed level of capital is defined as the model predicted level of capital plus a normally distributed white noise: $K^{o b s}=K+\varepsilon_{K}$, $\varepsilon_{K} \sim N\left(0, \sigma_{K}^{2}\right)$. Similarly the observed level of debt is the model predicted level plus the error term: $B^{o b s}=B+\varepsilon_{B}, \varepsilon_{B} \sim N\left(0, \sigma_{B}^{2}\right)$. This way, the observables do not need to coincide with their predicted levels. Instead of becoming zero, the likelihood value will decrease the higher the distance between the predicted levels of capital and debt and their empirical counterparts. The density for the first predicted levels of capital and debt thus becomes ${ }^{16}$

$f_{1}\left(K_{1}, B_{1}, \theta_{1}, \theta_{0} \mid K_{1}^{o b s}, B_{1}^{o b s}\right)=\frac{1}{\sigma} \phi\left(\frac{\theta_{1}-\gamma \theta_{0}-\mu}{\sigma}\right) w\left(\theta_{0} \mid K_{1}, B_{1}\right) \frac{1}{\sigma_{K}} \phi\left(\frac{K_{1}-K_{1}^{o b s}}{\sigma_{K}}\right) \frac{1}{\sigma_{B}} \phi\left(\frac{B_{1}-B_{1}^{o b s}}{\sigma_{B}}\right)$.

For the subsequent observations, we have a density function which is constructed with the densities of the measurement errors for capital and for debt. If we know $\left(K_{t}, B_{t}, \theta_{t}, \theta_{t-1}\right), K_{t+1}$ and $B_{t+1}$ are fully determined, which means that observed levels of investment and debt will have either probability one or zero. Adding measurement error to debt smooths out the likelihood function. Instead of one and zero, we have a density that increases as the distance between predicted and observed levels falls. Consequently, to compute the joint density distribution of true variables and observables, we include the density of the process for productivity and the density of

\footnotetext{
${ }^{16}$ We drop firm subscripts to economize on notation here.
} 
the measurement error in debt:

$$
\begin{aligned}
f_{t+1}\left(I_{t}^{o b s}, B_{t+1}^{o b s}, K_{t+1}, B_{t+1}, \theta_{t+1} \mid K_{t}, B_{t}, \theta_{t}, \theta_{t-1}\right) & =\frac{1}{\sigma} \phi\left(\frac{\theta_{t+1}-\gamma \theta_{t}-\mu}{\sigma}\right) \frac{1}{\sigma_{B}} \phi\left(\frac{B_{t+1}^{o b s}-B_{t+1}\left(K_{t}, B_{t}, \theta_{t}, \theta_{t-1}\right)}{\sigma_{B}}\right), \\
& \text { if } I_{t}^{o b s}=K_{t+1}\left(K_{t}, B_{t}, \theta_{t}, \theta_{t-1}\right)-(1-\delta) K_{t} \\
& =0, \text { otherwise. }
\end{aligned}
$$

With these conditional densities, we construct the density for the whole sequence of investment and debt. The individual likelihood contribution for the whole sequence of investment and debt conditional on the first observation is a product of densities for the predicted levels of capital and debt conditional on the observed levels.

$$
\begin{aligned}
\mathcal{L}_{i} & =f_{i T}\left(\left\{I_{i t}^{o b s}, B_{i t}^{o b s}\right\}_{t=2}^{T_{i}} \mid K_{i 1}^{o b s}, B_{i 1}^{o b s}\right) \\
& =\int . . \int \prod_{t=1}^{T_{i}-1} f_{i t+1}\left(I_{i t}^{o b s}, B_{i t+1}^{o b s}, K_{i t+1}, B_{i t+1}, \theta_{i t+1} \mid K_{i t}, B_{i t}, \theta_{i t}, \theta_{i t-1}\right) f_{i 1}\left(K_{i 1}, B_{i 1}, \theta_{i 1}, \theta_{i 0} \mid K_{i 1}^{o b s}, B_{i 1}^{o b s}\right) \prod_{t=0}^{T_{i}} d \theta_{i t}
\end{aligned}
$$

The integration is performed over all admissible values of $\left(\theta_{0}, \theta_{1}, \ldots, \theta_{T}\right)$, i.e. values of $\theta$ that imply $K$ and $B$ which do not violate the exit rule and other constraints. This is explained in greater detail in Appendix D.

The likelihood value for the whole sample is then computed using expression (7). The set of parameters to be estimated therefore is $\Theta=\{\alpha, \delta, \rho, \sigma, \mu, \gamma, s\} \cup\left\{\sigma_{K}, \sigma_{B}\right\}$ where the first set is the set of behavioral parameters of the model and the second set is the parameters of the measurement error distributions.

Notice that in the likelihood function $\gamma, \mu, \sigma$ enter as parameters of the process as well as inside the policy rules. These parameters are identified by the transitions of capital and debt period by period. As mentioned above, the other parameters of the structural model are identified mainly by debt and affect only the set of admissible values for observed capital and debt.

For the computation of this likelihood function,we exploit the discretization of the variables as described in Appendix B. The likelihood function is maximized using the Powell algorithm (Press, Teutolsky \& Vetterling 1992) which uses direction set 
methods to find the maximum. This algorithm relies on functional evaluations, not gradient methods.

\subsection{Results}

We estimate several versions of the model, the results of which are presented in Table 2. Asymptotic standard errors are calculated using the OPG estimator and provided in parenthesis below.

[Table 2 about here]

The first column represents the estimation of the model with full liquidity constraints, i.e. when $s=0$. As discussed in the previous subsection, all parameters are identified in this case. Since capital is the only factor of production in the model, we would expect an $\alpha$ of almost 1. However, the presence of the measurement errors, which throw a distribution around each initial permissible value of capital reduces $\alpha$ to 0.6 . The discount rate $\rho$ is estimated to be about $6 \%$ which is quite consistent with the average post war interest rates. The persistence parameter of the $\operatorname{AR}(1)$ shock $\gamma$ is estimated to be about 0.94. The idiosyncratic shock each period has a mean of 0.33 and a standard deviation of 0.21 . This implies that the shock has a high degree of persistence and that heterogeneity between firms is an important factor in explaining differences in behavior. The depreciation rate $\delta$ is estimated at 0.09 , which is somewhat smaller than the Hulten-Wykoff estimate for this sector of 0.12 . $\sigma_{K}$ is extremely large implying a large measurement error in the initial observation of capital. The capital stock series for a firm has been initialized using the book value of capital stock. The difference between the book and the economic value is, at least partially responsible for the measurement error. The standard deviation of the measurement error in debt is relatively small. The asymptotic standard errors of all parameters in this specification are small, suggesting a high degree of precision in our estimates.

The second column estimates the model with $s$ as a free parameter. We use 
the estimates of $\alpha, \rho$ and $\delta$ from the previous column and estimate the remaining parameters including $s$. As mentioned in the previous section, when $s=1, \alpha, \rho$ and $\delta$ are not identified. To allow for the possibility of $s$ being equal to 1 , we do not estimate these parameters. This specification returns an estimate of $s$ of around 0.73 . The other parameters, namely the mean, variance and the persistence parameter of the stochastic process are relatively similar to the previous column. A notable exception is the standard deviation on the measurement error of debt, which is much lower. The likelihood value is also significantly higher than in the previous case.

Finally, the third column presents estimates of the model without any liquidity constraints, i.e. with $s$ restricted to be 1 . The estimates of $\alpha, \rho$ and $\delta$ are again taken from the first column. The parameters are again quite similar to the first column, although the somewhat lower value of the likelihood function suggests that the model does not fit the data as well.

The rows marked $L R_{s=0}$ represents the likelihood ratio statistic from a test of the null hypothesis of $s=0$ against the alternate of $s \neq 0 .{ }^{17}$ As we can see, the null hypothesis is strongly rejected. Similarly $L R_{s=1}$ represents the likelihood ratio statistic for testing the null that $s=1$. Again, this null hypothesis is rejected.

One potential cause of concern is the magnitude of the measurement error on the initial observation of capital. To investigate whether this is driving our results, we estimated the next three columns, restricting the measurement error to have a standard deviation of $15 .^{18}$ The results of this estimation are in columns (4), (5) and (6). In column (4), which is the model with $s=0$, the estimate for $\alpha$ is very similar to that in column 1 . The risk free rate $\rho$ is slightly higher, as is $\delta$ and the mean and variance of the shock. This suggests that some variability in capital

\footnotetext{
${ }^{17}$ The models considered in this test (column (1) and column (2)) are not nested. However, imposing the estimated values of $\alpha, \rho$ and $\delta$ on the model of column (1) and estimating the remaining parameters gives us the same result as if we freely estimate all parameters. This implies that the first model differes from the second only in that $s$ is restricted to be 0 .

${ }^{18}$ Given the discretization of the capital stock, this is equivalent to restricting true capital to be one grid away (on either side) from observed capital.
} 
which was previously accounted for by $\sigma_{K}$ is now being accounted for by $\sigma_{\epsilon}$. The measurement error in debt is also slightly higher. The likelihood value is substantially lower, suggesting that the high measurement error in capital helps provide a better fit to the data. Similarly in column (5) the estimate of $s$ is not changed by the restriction on the measurement error. Again, $\delta, \mu$ are somewhat higher than in the previous case, and $\sigma_{\epsilon}$ is substantially higher. Similar results obtain in Column (6) where $s$ is restricted to be 1 . The likelihood ratio tests show that the null hypotheses of $s=0$ and $s=1$ are both rejected.

Another cause of concern is that the estimation of $s=0.73$ could be dependent on the values of the parameters $\alpha, \rho$ and $\delta$ which have been imposed to identify them. To check for the robustness of this result, we take the value of $\alpha, \rho$ and $\delta$ used in Cooley and Quadrini (2001) to calibrate their model and estimate the other parameters. The results are presented in columns (7) and (8). Column (7) shows that the value of $s$ is virtually unchanged. Restricting the measurement error in capital however, changes the value of $s$ to 0.34 . However, it is very clear that this value is neither zero, nor one, suggesting that some degree of liquidity constraints do exist.

\section{Comparison of the Model with the Data}

The analysis in the previous section suggests that the best fit for the data is provided by the specification in Column (2) of Table 2, i.e. where the degree of liquidity constraints are estimated. We therefore subject this model to further scrutiny to assess the goodness of fit. Using the parameters estimated we simulate time paths for capital and debt for 89 firms for 20 years. Figures 7 and 8 show the actual and predicted time paths for capital stock and debt in this model.

As we can see from Figure 7, the predicted values of average capital stock are much larger than actual data in the initial five or six years of the simulation. After that, predicted values of capital stock follow the data more closely. The reason for this 
is that in the initial periods, small firms tend to accumulate capital and there seems to be some overshooting. Large firms are more stable in size. Once firms converge to their steady state, we have a better fit of the data.Another reason could be the absence of any frictions (such as adjustment costs) other than the financial frictions in our model. Towards the end of the sample period, the actual and predicted values of capital stock converge.

Figure 8 shows the predicted path of debt as compared to the actual path. As in the previous picture, the model overpredicts the level of debt initially. This overprediction can be explained jointly with the overprediction of capital stock for those years. By 1988, the model predicted and the data series are much closer and also move together. This is analogous to what happens to capital.

\subsection{Goodness of Fit Tests}

We perform goodness of fit tests to measure the distance between the observed and model predicted distributions of capital and debt. A $\chi^{2}$ statistic provides cell-by-cell information on whether the observed data comes from the probability distribution implied by the theoretical model. Let $n_{j t}$ be the actual number of observations of choice $j$ at time $t$ and $\hat{n}_{j t}$ be the model predicted counterpart. The simplest test statistic across choices $j$ at time $t$ is defined as $\chi^{2}=\Sigma_{j=1}^{J} \frac{\left(n_{j t}-\hat{n}_{j t}\right)^{2}}{\hat{n}_{j t}}$, where $J$ is the total number of possible choices and $T$ is the number of years. $\chi^{2}$ has an asymptotic $\chi^{2}$ distribution with $J-1$ degrees of freedom.

We divide capital stock and debt into five bins each to conduct this test. These categories are basically a contracted version of the discrete state space, ${ }^{19}$ chosen to correspond to the actual distribution of capital stock and debt in the data.

The $\chi^{2}$ statistic is presented in Table 3 . The statistic for the first year is zero because the model predicted distribution is generated using the first observation on

\footnotetext{
${ }^{19}$ For capital the categories are: 0-200, 200-400, 400-600, 600-800, $\geq 800$ million dollars. For debt, the categories are 0-100, 100-200, 200-300, 300-400, $\geq 400$ million dollars.
} 
capital and debt in the data which makes the two distributions identical for the initial year. As was obvious even from the simple graphical comparison, the fit for the subsequent five years for capital is not very good. Thereafter the statistic is significant at the $5 \%$ level of significance for every year except $1984 .{ }^{20}$ Similarly the $\chi^{2}$ statistic for debt is not significant for 1977, but the fit improves for the subsequent two years. The statistic is not significant for the period of 1980 to 1984, but it is always significant after 1984 .

[Table 3 about here]

It should be noted that our criterion for testing goodness of fit is particularly stringent. If the model does not fit at time $t$, the fit at $t+1$ is even more difficult to obtain since the variables are related. In general, we would expect structural models to perform worse than reduced form models in goodness of fit tests since the former make far greater demands on the data than the latter. The clear advantage of structural models over reduced form models is that they allow us to conduct policy experiments.

\section{Policy Experiments}

We are now in a position to use the parameters we have estimated to quantify the importance of liquidity constraints for firm investment. This is done with the help of two policy experiments. In the first experiment we assess the effect of relaxing the dividend constraint. As a baseline, we use the parameters from the second column of Table 2 to simulate the time paths of capital for all firms. We then simulate the time path of capital for different values of $s$ and compare these time paths to the baseline. This gives us an idea of the importance of the dividend constraint in terms of investment forgone.

The second policy experiment is designed to quantify the effect of the "financial

\footnotetext{
${ }^{20}$ The critical value in both cases is 9.49 at the $5 \%$ level of significance and 11.14 at the $99 \%$ level.
} 
accelerator", namely the changes in capital stock as a result of transitory changes in the firms' financial position. We study the response of firms to a transitory $1 \%$ change in the risk free rate. This raises the cost of borrowing for one period, but does not affect the subsequent periods. The transitory shock does not affect firms who do not have a dividend constraint, i.e. for whom $s=1$ because their investment is not sensitive to their financial position.

\subsection{Relaxing the Dividend Constraint}

As mentioned earlier, the effect of changing $s$ is not uniform for all firms. While increasing $s$ allows small firms to accumulate more capital on one hand, it also reduces the need for precautionary capital accumulation on the other. Hence when $s=1$, firms with low $x$ will accumulate more and firms with high $x$ will accumulate less as compared to when $s<1$.

The results of this exercise are presented in Table 4. We simulate capital stocks for $s=0, s=0.73$ and $s=1$. Additionally, Figure 9, 10 and 11 compare the average capital stock for all, small and large firms respectively for $s=0.73$ and $s=1$. Small firms are defined as firms with less than an initial value of capital of $\$ 100$ million.

[Table 4 about here]

As Figure 9 shows, firms with $s=1$ are able to accumulate more capital than firms with $s=0.73$ in the initial 10 years. Five years after we begin the simulation, the difference in capital stock is about $\$ 14$ million or $8 \%$. This difference narrows as firms reach their steady state. Within ten years, the difference is halved to $\$ 7$ million or $4 \%$ and by the fifteenth year it disappears. Over a period of 20 years, the average effect of increasing $s$ from 0.73 to 1.0 is about $6.07 \%$.

A very similar pattern is observed when we look at the accumulation of small firms (Figure 10). A relatively wide initial divergence (about $\$ 12$ million in the fifth year of the simulation) narrows to $\$ 7$ million ten years after we start the simulation. By the fifteenth year, this gap has disappeared. The overall difference in capital stock 
for small firms is about $7 \%$.

The behavior of large firms is however different. In the initial years capital stock in the $s=1$ case is higher than in the benchmark case. However this relationship gets reversed about six years after the simulation begins when most firms have reached their desired level of capital. In the fifth year of the simulation, firms with unrestricted dividends have on the average, capital stock of $\$ 2$ million dollars more than those with $s$ restricted to 0.73 . However, by the tenth year, their capital stock falls to $\$ 1.5$ million less than the benchmark firms. The overall difference for 20 years is about $2 \%$.

Turning now to the comparison of the average capital stock of firms with $s=0$, i.e. full liquidity constraints and $s=0.73$ we see that the former have significantly lower average capital stock than the latter. Over the 20 year period, this averages to about $9 \%$ for all firms. For small and large firms, the figure is $10 \%$ and $3.6 \%$ respectively for the entire period. Table 4 also shows that a large part of this difference is accounted for in the first five years. For small firms this is about $\$ 20$ million or $13 \%$ of the total capital stock. This reduces to about $7 \%$ within 10 years and to about $1 \%$ by 15 years. For large firms, the corresponding figures are an $8 \%$ difference for the fifth year. By the tenth year, the capital stocks of both types of firms are very similar.

Thus we see that relaxing the dividend constraint has substantial consequences for the accumulation of capital stock. However, a simple relaxation of the dividend constraint is not enough to increase investment. While firms with low $x$ increase their capital, the capital accumulation of large firms is lower than in the benchmark case. In a sample dominated by large firms therefore, it is conceivable that the relaxation

of this constraint could actually cause a decline in overall capital stock. Our sample mainly consists of small firms and so the net effect of relaxing the constraint is positive.

\subsection{Transitory Changes in $x$}

As mentioned before, the second experiment consists of increasing the risk free rate by $1 \%$ in the first period of the simulation and allowing it to go back to its estimated 
value subsequently. However we do not change the discount rate, so this experiment leaves the fundamentals of the firm unaltered. Since this transitory change reduces $x$, we would expect $K^{\prime}$ to decline for firms whose capital stock is sensitive to their financial position.

Figure 12 shows the effect of this exercise on firms whose dividends are partially constrained by $s=0.73$. The dotted line shows the impact on small firms (defined as in the previous section) and the solid line on large firms. As we can see from the graph, the effects of a transitory shock to interest rates can be felt for 8 subsequent periods for small firms. In the first period after the shock, capital stock reduces by $2.8 \%$ and in the second period by $3 \%$. In the fifth period after the shock, the reduction in capital stock is of the order of $1.5 \%$ and in the eight year it is $0.6 \%$ before going down to zero. For large firms, the effect of this transitory shock is smaller and less persistent, in fact it peters out by the sixth period after the shock.

This transitory shock has no effect on firms which are allowed to issue unlimited equity, i.e. when $s=1$. A reduction in $x$ as a result of the rise in interest rates is compensated for by an increase in equity and the firms are able to maintain the same levels of capital stock as before.

Hence we see that in our model, we are able to capture the effect of the financial accelerator on firms' investment. The presence of liquidity constraints amplifies small shocks to firms' financial position, leading to persistent changes in capital stock. These changes are greater and last longer for smaller firms as compared to larger firms. These shocks have no effect on firms who do not operate under these liquidity constraints and are allowed to issue fresh equity, since the reduction in internal funds can be made up by external funds. 


\section{Conclusions}

We set up a dynamic model of firm investment which incorporates liquidity constraints into a firm's decision making process. We find that investment is positively related to the firm's financial position when it has a low level of internal funds. This relationship disappears once the firm reaches its desired level of capital stock and further improvements in its financial position do not induce additional investment. Borrowing initially increases with the firm's financial position. However, as its capital stock moves closer to the desired level, debt falls. Thereafter, the firm maintains a very low level of borrowing, regardless of the value of its financial position.

Our model allows us to test of the degree of liquidity constraints as a restriction on the lower bound on the dividends that a firm pays out. We estimate this model using the firms' decision rule as an input into the likelihood function. While our estimates reject the specifications of total constraints and no constraints, they do suggest that firms operate under some degree of liquidity constraints.

Goodness of fit tests show that the model is able to predict the path of capital stock for the latter part of the sample well, in the initial period, it overestimates the amount of capital a firm accumulates. This is also true for debt.

With these parameter estimates it is possible to quantify the importance of the liquidity constraint for capital accumulation. Relaxing the non negativity of the dividend constraint completely allows firms to accumulate, on the average, $6 \%$ more capital as compared to the case where dividends are partially constrained. If we compare firms whose dividends are constrained to be non-negative to those whose dividends are constrained partially, we find that the latter are able to accumulate, on the average, about $9 \%$ more capital than the former.

The presence of liquidity constraints also amplifies and propagates small negative shocks to the firms' financial position. A transitory shock to the financial position of small firms which are not allowed to issue equity, reduces capital for 8 subsequent periods. For large firms the effect is smaller and less persistent. However this shock 
has no impact on firms which have no limits on issuing fresh equity because the reduction in internal funds can be compensated for by external funds. 


\section{Appendix A}

\section{A.1. Endogenous interest rate}

The interest rate solves $G\left(r^{\prime}\right)=0$, which may not yield a unique solution for $r^{\prime}$ given $K^{\prime}$, $B^{\prime}$ and $\theta$ as it is not monotonically increasing in $r^{\prime}$ :

$$
G^{\prime}\left(r^{\prime}\right)=1-\Phi\left(\kappa^{\prime}\right)-\frac{1}{\sigma} \phi\left(\kappa^{\prime}\right) B^{\prime} K^{\prime \alpha}\left(1+r^{\prime}\right)
$$

When there are multiple solutions, competition between lenders will lead to the lowest of these rates. Since $G(\rho)=-\Phi\left(\kappa^{\prime}\right)<0$, if at least one equilibrium rate exists, there is a low value of $r^{\prime}$, such that $G^{\prime}\left(r^{\prime}\right) \geq 0$, implying $1-\Phi\left(\kappa^{\prime}\right) \geq \frac{1}{\sigma} \phi\left(\kappa^{\prime}\right) \frac{B^{\prime}}{K^{\prime \alpha}}\left(1+r^{\prime}\right)$ and $\Upsilon>0$. Using the implicit function $G\left(r^{\prime}\right)$ we obtain the derivatives of the interest rate function over its arguments shown in Subsection 2.1.

\section{A.2. Proofs of propositions}

\section{Proof of Proposition 1 From $L_{B^{\prime}}$}

$$
\begin{array}{r}
\widetilde{E} V_{2}+r_{B^{\prime}} \widetilde{E} V_{4}=-(1+\rho) \\
B^{\prime}=-(1+\rho) \frac{\left(1-\Phi\left(\kappa^{\prime}\right)\right) \widetilde{E} \xi^{\prime}}{r_{B^{\prime}}\left(1-\Phi\left(\kappa^{\prime}\right)+\widetilde{E} \xi^{\prime}\right)}<0
\end{array}
$$

Debt would be negative which is infeasible. So, a solution must hit at least one constraint

Proof of Proposition 2 (i) We proceed inductively. Starting at an initial iteration at $n=0$ with $K_{0}^{* * *}(\theta)=K_{n d}(\theta)$, then $\xi_{0}=0$, for all $x$. Then $\widetilde{E} \xi_{0}=0$ and $\widetilde{E}\left(\theta_{0} \xi_{0}\right)=0$, implying $K_{1}^{* * *}(\theta)=K_{n d}(\theta)$. Consequently, $K_{1}^{* * *}(\theta)-s K_{n d}(\theta) \leq 0$, and any firm with $x \geq 0$ can attain $K_{n d}(\theta)$. The argument is repeated for all $n>0$, so the stationary policy rule attained at $n \rightarrow \infty$ is $K^{* * *}(\theta)=K_{n d}(\theta)$.

(ii) Suppose that $K^{* * *}(\theta) \leq s K_{n d}(\theta)$, this means that $K^{* * *}(\theta)-s K_{n d}(\theta) \leq 0$, so any firm with $x \geq 0$ will be in regime III. This means that $\xi=0$, thus $\widetilde{E} \xi=0$ and $\widetilde{\widetilde{E}}(\theta \xi)=0$. This implies that $K^{* * *}(\theta)=K_{n d}(\theta)$, which is not possible because $s<1$, contradicting thereby the assumption

Proof of Proposition 3 If $s \geq 1, K^{* * *}(\theta)=K_{n d}(\theta)$, and all firms are in regime III, so the proposition holds.

If $s<1$, only firms with $x \geq K^{* * *}(\theta)-s K_{n d}(\theta)>0$ will be in regime III. Firms with $x<K^{* * *}(\theta)-s K_{n d}(\theta)$ will be in regime $I$ or $I I$

\section{A.3. Capital in Regime I}

The first order condition for capital can be written as

$$
L_{K^{\prime}}=\widetilde{E} V_{1}+\widetilde{E} V_{2}+\left(r_{K^{\prime}}^{\prime}+r_{B^{\prime}}^{\prime}\right) \widetilde{E} V_{4}=0,
$$

and its second derivative is

$$
-L_{K^{\prime} K^{\prime}}=-\widetilde{E} V_{11}-\widetilde{E} V_{21}-\left(r_{K^{\prime}}^{\prime}+r_{B^{\prime}}^{\prime}\right) \widetilde{E} V_{41}-\left(r_{K^{\prime} K^{\prime}}^{\prime}+r_{B^{\prime} K^{\prime}}^{\prime}\right) \widetilde{E} V_{4}>0,
$$


at the maximum. Then using $r_{K^{\prime}}^{\prime}+r_{B^{\prime}}^{\prime}>0$, and

$$
L_{K^{\prime} x}=-\left(r_{K^{\prime}}^{\prime}+r_{B^{\prime}}^{\prime}\right) \widetilde{E} V_{41}=\left(r_{K^{\prime}}^{\prime}+r_{B^{\prime}}^{\prime}\right)\left(1-\Phi\left(\kappa^{\prime}\right)+\widetilde{E} \xi^{\prime}\right)>0,
$$

we obtain $K_{x}=\frac{L_{K^{\prime} x}}{-L_{K^{\prime} K^{\prime}}}>0$. Moreover $K_{x}<(>,=) 1$ if $-L_{K^{\prime} K^{\prime}}-L_{K^{\prime}}=-\widetilde{E} V_{11}-\widetilde{E} V_{21}-$ $\left(r_{K^{\prime} K^{\prime}}^{\prime}+r_{B^{\prime} K^{\prime}}^{\prime}\right) \widetilde{E} V_{4}>(<,=) 0$.

\section{B: Numerical Solution of the Model}

As mentioned in the main body of the paper, the model is solved by value function iteration, on a discretized state space. Details of the discretization are given in the table below.

\begin{tabular}{llll}
\hline \hline $\begin{array}{c}\text { Original } \\
\text { variable }\end{array}$ & $\begin{array}{l}\text { Discretized } \\
\text { variable }\end{array}$ & Grid of points & $\begin{array}{l}\text { Number } \\
\text { of gridpoints }\end{array}$ \\
\hline \hline$x$ & $x(m) ;$ & $m=1, \ldots, N_{x} ;$ & $N_{x}=50$ \\
$\theta$ & $\theta(s) ;$ & $s=1, \ldots, N_{\theta} ;$ & $N_{\theta}=51$ \\
$K$ & $K(i) ;$ & $i=1, \ldots, N_{K} ;$ & $N_{K}=50$ \\
$B$ & $B(j) ;$ & $j=1, \ldots, N_{B} ;$ & $N_{B}=50$ \\
\hline
\end{tabular}

The probability distributions are also discretized.

$$
\operatorname{Pr}\left(s^{\prime} \mid s\right)=g\left(s^{\prime} \mid s\right)=\Phi\left(\frac{\theta\left(s^{\prime}\right)-\gamma \theta(s)+\Delta_{\epsilon} / 2-\mu}{\sigma_{\epsilon}}\right)-\Phi\left(\frac{\theta\left(s^{\prime}\right)-\gamma \theta(s)-\Delta_{\epsilon} / 2-\mu}{\sigma_{\epsilon}}\right)
$$

where $s^{\prime}=1,2, \ldots . N_{\theta}$ and $s=1,2, \ldots . N_{\theta}$. The grid size is $\Delta_{\epsilon}=\frac{6 \sigma_{\epsilon}}{N_{\epsilon}}$.

The numerical solution proceeds in the following steps

1. Calculate interest rates $r^{\prime}$ with a bracketing and bisection routine on the equation

$$
\left[1+r^{\prime}\left(K^{\prime}(i), B^{\prime}(j), \theta(s)\right)\right] \operatorname{Pr}\left(\theta^{\prime} \geq\left(1+r^{\prime}\right) B(j)^{\prime} K^{\prime \alpha}(i)-(1-\delta) K^{\prime}(i)^{\alpha-1} \mid \theta(s)\right)-(1+\rho)=0
$$

In case of multiple solutions, we choose the smallest one. The solution $r(i, j, s)$ gives us the interest rate charged to a firm with a realized shock of $\theta(s)$ today who wishes to borrow $B^{\prime}(j)$ and have capital stock $K^{\prime}(i)$ tomorrow. This also gives us the value of $\underline{\theta}^{\prime}(i, j, s)$, the threshold value of the shock, below which the firm exits. This is the realization of the shock $\theta^{\prime}$ tomorrow, for a firm with capital stock $K^{\prime}$ and debt $B^{\prime}$ which will render it unable to pay its obligations.

2. Starting with an initial value of the value function $\widehat{V}_{0}(x(m), \theta(s))$, and defining $\widehat{V}_{n}$ as the $n^{\text {th }}$ iteration we construct

$$
\widehat{V}_{n}(x(m), \theta(s))=\max _{i, j} x(m)-K^{\prime}(i)+B^{\prime}(j)+\frac{1}{1+\rho} \sum_{s^{\prime}=1}^{N_{\theta}} \widehat{V}_{n-1}\left(x\left(m^{\prime}\right), \theta^{\prime}\left(s^{\prime}\right)\right) P\left(s^{\prime} \mid s\right)
$$


where the following conditions must be satisfied

$$
\begin{aligned}
x\left(m^{\prime}\right) & =\theta^{\prime}\left(s^{\prime}\right) K^{\prime}(i)^{\alpha}+(1-\delta) K^{\prime}(i)-\left(1+r^{\prime}\right) B^{\prime}(j), \\
r^{\prime} & =r^{\prime}(i, j, s), \\
x(m)-K^{\prime}(i)+B^{\prime}(j) & \geq \bar{D}
\end{aligned}
$$

The first of the above equations is simply the definition of $x^{\prime}$. The second incorporates the zero profit condition for the banks and the last imposes the dividend constraint. ${ }^{21}$

This is done for all $m=1,2, \ldots N_{x}$ and $s=1,2, \ldots ., N_{\theta}$.

3. This process is repeated until the tolerance criterion $\omega$ is met, i.e.

$$
\max \left|\widehat{V}_{n}(x(m), \theta(s))-\widehat{V}_{n-1}(x(m), \theta(s))\right| \leq \omega
$$

4. The policy rules for capital $K(m, s)$ and for debt $B(m, s)$ are

$$
\begin{aligned}
K(x(m), \theta(s)) & =K^{*}(i) \\
B(x(m), \theta(s)) & =B^{*}(j)
\end{aligned}
$$

where $K^{*}(i)$ and $B^{*}(j)$ are the $\operatorname{argmax}$ of $V_{n}(x(m), \theta(s))$.

\section{Appendix C: Data}

\section{C.1. Sample Selection}

The data used are from Standard \& Poor's Industrial Compustat files for SIC code 34. Our initial sample consisted of an unbalanced panel of 328 firms and 3088 observations over the period 1976 to 1995 for which data on $I$ and $B$ were available. We discarded firms from the sample if they has data for less than 10 years, zero book value of capital stock for any year, a missing value of capital stock for the initial observation or if there were any gaps in the data on $K$ and $B$. In addition, we also removed outliers using the method described below.

\section{C.2. Rule for Removing Outliers}

Following Gilchrist \& Himmelberg (1995), we use this rule to eliminate firms who have major changes in the value of their capital stock due to reasons other than changes in investment. Under standard accounting procedures the gross book value of physical capital $B K_{t}$ satisfies the following identity:

$$
B K_{t}=B K_{t-1}+I_{t}-R_{t}+O_{t}
$$

where $R$ is retirements and $O$ is other changes in property, plant and equipment which have not been accounted for elsewhere. We exclude firms for which

$$
\left|B K_{t}-B K_{t-1}-I_{t}+R_{t}\right| \geq 0.3 B K_{t-1}
$$

in any year.

${ }^{21} \bar{D}=0$ is straightforward to estimate. When $\bar{D}=-s K_{n d}(\theta)$, we first compute $K_{n d}(\theta)$ for each value of $\theta$ by iterating on the value function without the dividend constraint till it converges. 


\section{C.3. Construction of Replacement Value of Capital Stock}

We use the value of firm investment every year to construct a series for the replacement value of capital stock. The series is initialized with the book value of capital for the first year. We use the perpetual inventory method for constructing capital stock. The replacement value of capital stock $K_{t}$ is defined as

$$
K_{t}=(1-\delta) K_{t-1}+I_{t}
$$

where $I$ is the firm's investment for year $t$ and $\delta$ is the depreciation rate. The value of $\delta$ used is the Hulton-Wykoff estimate for this industry group. Later, the estimated value of $\delta$ is used to re construct the capital stock. The latter value is used for the chi square tests.

All data are previously deflated using the GDP deflator $(1984=100)$. The table below summarizes the information about data selection

\begin{tabular}{lr}
\hline \hline Initial No. of firms & 328 \\
Firms with data for 10 or more years & 128 \\
Firms with capital stock $>0$ for all years & 124 \\
Firms with initial value of $K$ given & 123 \\
Firms with no gaps in $I$ and $B$ & 118 \\
Firms with no unexplained jumps in capital stock & 89 \\
\hline \hline
\end{tabular}

\section{Appendix D: Likelihood function}

To construct the likelihood function, we exploit the discretization of the continuous variables to solve the DP problem and compute the likelihood as a Markov chain (Rendón 1997). The construction of this function requires multiple integrations, actually summations, which can be simplified by a recursive computation. As we did with the Bellman equation, we exploit the fact that the state variables can be written as $x$ and $\theta$.

As defined in Appendix B, $g\left(s^{\prime} \mid s\right)$ is the probability of $\theta\left(s^{\prime}\right)$ conditional on $\theta(s)$ (equation $(9)) ; i^{\prime}(m, s)$ and $j^{\prime}(m, s)$ are the policy rules for capital and debt, respectively, in terms of the ordinals of $K^{\prime}\left(i^{\prime}\right)(x(m), \theta(s))$ and $B^{\prime}\left(j^{\prime}\right)(x(m), \theta(s))$ - The discretized densities of measurement errors in capital and in debt are given by

$$
\begin{aligned}
h_{K}\left(i_{K}\right) & =\Phi\left(\frac{\epsilon_{K}\left(i_{K}\right)+\Delta_{K} / 2}{\sigma_{K}}\right)-\Phi\left(\frac{\epsilon_{K}\left(i_{K}\right)-\Delta_{K} / 2}{\sigma_{K}}\right) \\
h_{B}\left(i_{B}\right) & =\Phi\left(\frac{\epsilon_{B}\left(i_{B}\right)+\Delta_{B} / 2}{\sigma_{B}}\right)-\Phi\left(\frac{\epsilon_{B}\left(i_{B}\right)-\Delta_{B} / 2}{\sigma_{B}}\right)
\end{aligned}
$$

where $i_{K}$ indexes the discretized version of $\epsilon_{K}$ and $i_{B}$. indexes $\epsilon_{B} \sigma_{K}$ and $\sigma_{B}$ are the standard deviations of $\epsilon_{K}$ and $\epsilon_{B}$ while $\Delta_{K}$ denotes the grid size for capital and $\Delta_{B}$ for debt, respectively.

Since we construct the capital stock using data on investment and $\delta$, the capital stock will have to be reconstructed at each iteration with the new value of $\delta$. This means that, together with the state variables $x(m)$ and $\theta(s)$ we have to keep track of capital stock at each period. This is not needed for debt, whose value can be subsumed into that of $x(m)$. Let us define $\Lambda(i, m, s)^{t}$ as the joint probability of reaching capital $K(i)$, financial resources $x(m)$, and productivity $\theta(s)$ at time $t$ and observing the past sequence of capital and debt 
up to this point:

$$
\Lambda(i, m, s)^{t}=\operatorname{Pr}\left(K(i), x(m), \theta(s),\left\{i_{l}^{o b s}, j_{l}^{o b s}\right\}_{l=2}^{t} \mid i_{1}^{o b s}, j_{1}^{o b s}\right)
$$

In the first period we compute the discrete version of function $w\left(\theta_{0} \mid K_{1}, B_{1}\right)$. Let

$$
\begin{aligned}
I\left(i_{1}, j_{1} \mid m_{0}, s_{0}\right) & =1, \text { if } i_{1}=i_{1}\left(m_{0}, s_{0}\right), \text { and } j_{1}=j_{1}\left(m_{0}, s_{0}\right) \\
& =0, \text { otherwise. }
\end{aligned}
$$

The probability for the productivity level $s_{0}$ given $\left(i_{1}, j_{1}\right)$ is then:

$$
\operatorname{Pr}\left(s_{0} \mid i_{1}, j_{1}\right)=\frac{\sum_{m} I\left(i_{1}, j_{1} \mid m, s_{0}\right)}{\sum_{s} \sum_{m} I\left(i_{1}, j_{1} \mid m, s\right)}
$$

Both summations go over the whole discretized state space, selecting only admissible values for the originating combinations of $x_{0}$ and $\theta_{0}$. We compute next the discrete version of equation (8) using the state space $x, \theta$, while keeping track of capital. Thus, the joint probability of reaching capital $K\left(i_{1}\right)$, financial resources $x\left(m_{1}\right)$ and shock $\theta\left(s_{1}\right)$ conditional on the first observation of capital and debt is

$$
\Lambda\left(i_{1}, m_{1}, s_{1}\right)^{1}=\sum_{j_{1}} \sum_{s_{0}} g\left(s_{1} \mid s_{0}\right) \times \operatorname{Pr}\left(s_{0} \mid i_{1}, j_{1}\right) \times h_{K}\left(i_{1}-i_{1}^{\text {obs }}\right) \times h_{B}\left(j_{1}-j_{1}^{\text {obs }}\right)
$$

In the right hand side, the expression inside the double summation is the joint probability of a productivity levels $s_{1}$ and $s_{0}$ and of true levels of capital and debt $i_{1}$, and $j_{1}$, conditional on observing $K\left(i_{1}^{\text {obs }}\right)$ and $B\left(j_{1}^{\text {obs }}\right)$. Since we only need to keep track of $\left(i_{1}, m_{1}, s_{1}\right)$, we integrate over $s_{0}$ and $j_{1}$.Starting off from this first observation, $\Lambda(i, m, s)^{t}$ can be defined recursively in the following manner:

$$
\Lambda\left(i^{\prime}, m^{\prime}, s^{\prime}\right)^{t+1}=\sum_{i} \sum_{x(m) \geq 0} \sum_{s} \Lambda(i, m, s)^{t} \times g\left(s^{\prime} \mid s\right) \times h_{B}\left(j^{\prime o b s}-j^{\prime}(m, s)\right)
$$

$\Lambda\left(i^{\prime}, m^{\prime}, s^{\prime}\right)^{t+1}$ is defined analogously to $\Lambda(i, m, s)^{t}$ as the joint probability of reaching capital $K\left(i^{\prime}\right)$, financial resources $x\left(m^{\prime}\right)$ and productivity $\theta\left(s^{\prime}\right)$ and observing the past sequence of debt and capital at time $t+1$. For each value of the unobservables $K(i), x(m)$ and $\theta(s)$, we have to compute the probability of moving to capital $K^{\prime}(i)$, debt $B^{\prime}(j)$ and shock $\theta\left(s^{\prime}\right)$, and assign them to the implied values of $x\left(m^{\prime}\right) \geq 0$. We include in this recursive computation a measurement error for debt, not for capital. The likelihood contribution for firm $n$ can be computed by integrating $\Lambda(i, m, s)^{T_{l}}$ over all possible values of the unobservables $x(m)$, $K(i)$ and $\theta(s)$, i.e.

$$
\mathcal{L}^{n}=\operatorname{Pr}\left(\left\{i_{l}^{\text {obs }}, j_{l}^{\text {obs }}\right\}_{l=2}^{t} \mid i_{1}^{\text {obs }}, j_{1}^{\text {obs }}\right)=\sum_{i} \sum_{x(m) \geq 0} \sum_{s} \Lambda(i, m, s)^{T_{l}}
$$

Notice that the unobservable true values only intervene in the expressions to facilitate the recursive computation of multiple integrals. At the end of the iteration, the likelihood function is the probability of observing the data given certain parameter values. 


\section{References}

[1] Abel, A. B. \& Eberly, J. (1995), Investment and Q with Fixed Costs: An Empirical Analysis, mimeo, University of Pennsylvania.

[2] Alberquerque R. \& H. Hopenhayn (1997), Optimal Dynamic Lending Contracts with Imperfect Enforceability', mimeo, University of Rochester.

[3] Attanasio, O P. (1995), 'The intertemporal allocation of consumption: Theory and evidence', Carnegie Rochester Series on Public Policy 42, 39-89.

[4] Barnett, S. A. \& Sakellaris, P. (1998), 'Non-linear response of Firm Investment to Q: Testing a model of convex and non-convex adjustment costs', Journal of Monetary Economics 42, 67-92.

[5] Bernanke, B. \& Gertler, M. (1989), 'Agency costs, net worth, and business fluctuations', American Economic Review 79, 14-31.

[6] Bernanke, B. \& Gertler, M. (1990), 'Financial fragility and economic performance', Quarterly Journal of Economics 105, 97-114.

[7] Bernanke, B., Gertler, M. \& Gilchrist, S. (1996), 'The financial accelerator and the flight to quality', Review of Economics and Statistics 78, 1-15.

[8] Bernanke, B., Gertler, M. \& Gilchrist, S. (1999), The Financial Accelerator in a Quantitative Business Cycle Framework, in J.B. Taylor \& M. Woodford ed. 'Handbook of Macroeconomics', Elsevier North Holland.

[9] Bond, S. \& Meghir, C. (1994), 'Dynamic investment models and the firm's financial policy', Review of Economic Studies 61, 197-222.

[10] Clementi, G. (2000), 'IPOs and the Growth of Firms', mimeo, Carnegie Mellon University.

[11] Cooley, T.F, Marimon, R. \& Quadrini V. (1999) 'Aggregate Consequences of Limited Enforceability', mimeo, New York University.

[12] Cooley, T.F. \& Quadrini, V. (2001), 'Financial Markets and Firm Dynamics', American Economic Review, 91, 1286-1310.

[13] Devereux, M. \& Schiantarelli, F. (1989), Investment, financial factors, and cash flow: Evidence from U.K. panel data, in R. G. Hubbard, ed., 'Asymmetric Information, Corporate Finance, and Investment', The University of Chicago Press, Chicago, pp. 279306.

[14] Doms, M. \& Dunne, T. (1998), 'Capital Adjustment in Manufacturing Plants', Review of Economic Dynamics, 1, 409-429.

[15] Eraslan, H. (2000) 'Corporate Bankruptcy Reorganization: Estimates from a Bargaining Model', mimeo, University of Pennsylvania.

[16] Evans, D.S. (1987), 'Tests of Alternative Theories of Firm Growth', Journal of Political Economy, 95, 657-674. 
[17] Fazzari, S. M., Hubbard, R. G. \& Petersen, B. C. (1988), 'Financing constraints and corporate investment', Brookings Papers on Economic Activity 1, 141-195.

[18] Gertler, M. (1988), 'Financial structure and aggregate economic activity: An overview', Journal of Money, Credit, and Banking 20, 559-588.

[19] Gertler, M. \& Gilchrist, S. (1994), 'Monetary policy, business cycles and the behavior of small manufacturing firms', Quarterly Journal of Economics 109, 309-340.

[20] Gertler, M., Hubbard, R. G. \& Kashyap, A. (1991), Interest rate spreads, credit constraints and investment fluctuations: An empirical investigation, in R. G. Hubbard, ed., 'Financial Markets and Financial Crises', The University of Chicago Press, Chicago, pp. 11-31.

[21] Gilchrist, S. \& Himmelberg, C. P. (1995), 'Evidence on the role of cash flow for investment', Journal of Monetary Economics 36, 541-572.

[22] Gilchrist, S. \& Himmelberg, C. P. (1998), 'Investment, Fundamentals and Finance', NBER Working Paper No. 6652.

[23] Gomes, J.F. (2001), 'Financing Investment', American Economic Review, 91, 12631285.

[24] Greenwald, B. C., Stiglitz, J. E. \& Weiss, A. (1984), 'Informational imperfections in the capital market and macroeconomic fluctuations', American Economic Review 74, 194-200.

[25] Gross, D. (1994), The investment and financing decisions of liquidity constrained firms, mimeo, Massachusetts Institute of Technology.

[26] Hall, B.H. (1987), 'The Relationship between Firm Size and Firm Growth in the U.S. Manufacturing Sector', Journal of Industrial Economics, 35, 583-606.

[27] Hall, B.H. \& Hall R.E., (1993), 'The Value and Performance of U.S. Corporations', Brookings Papers on Economic Activity, 1, 1-34.

[28] Hoshi, T., Kashyap, A. \& Scharfstein, D. (1991), 'Corporate structure, liquidity, and investment: Evidence from Japanese industrial groups', Quarterly Journal of Economics 106, 33-60.

[29] Hubbard, R. G. (1998), 'Capital market imperfections and investment', Journal of Economic Literature 36, 193-225.

[30] Ito, Harumi (1996), The Structure of Adjustment Costs in Mainframe Computer Investment, Working Paper No. 96/29, Department of Economics, Brown University.

[31] Kaplan, S. N. \& Zingales, L. (1997), 'Do investment-cash flow sensitivities provide useful measures of financial constraints?', Quarterly Journal of Economics 112, 169216.

[32] Kehoe, T.J. \& Levine, D.K. (1993), 'Debt-Constrained Asset Markets' Review of Economic Studies, 60, 865-888.

[33] Kocherlakota, N. (1996), 'Implications of Efficient Risk Sharing without Commitment', Review of Economic Studies, 63, 595-609. 
[34] Kwan, E. (1994), Role of financing constraints on firms' investment: Evidence from the retail trade sector, mimeo, New York University.

[35] Modigliani, F. \& Miller, M. (1958), 'The cost of capital, corporation finance, and the theory of investment', American Economic Review 38, 261-297.

[36] Myers, S. C. \& Majluf, N. S. (1984), 'Corporate financing and investment decisions when firms have information that investors do not have', Journal of Financial Economics 13, 187-221.

[37] Ng, S. \& Schaller, H. (1996), 'The risky spread, investment, and monetary policy transmission: Evidence on the role of asymmetric information', Review of Economics and Statistics 78, 375-383.

[38] Pratap, S. (forthcoming), Do Adjustment Costs Explain Investment Cash Flow Insensitivity? Journal of Economics Dynamics and Control

[39] Press, W. H., Teutolsky, S. A., Vetterling, W. T. \& Flannery, B. P. (1992), Numerical Recipes in FORTRAN: The Art of Scientific Computing, Cambridge University Press, New York.

[40] Rendón, S. (1997), Job Search and Asset Accumulation under Borrowing Constraints, PhD thesis, New York University, New York.

[41] Rendón, S. (1999), Job Creation under Borrowing Constraints: The Spanish Case, mimeo, Universitat Pompeu Fabra.

[42] Schaller, H. (1993), 'Asymmetric information, liquidity constraints, and Canadian investment', Canadian Journal of Economics 26, 552-574.

[43] Schiantarelli, F. \& Sembellini, A. (2000), 'Form of Ownership and Financial Constraints', Empirica, 27, 175-192.

[44] Whited, T. M. (1992), 'Debt, liquidity constraints and corporate investment: Evidence from Panel Data', Journal of Finance 47, 1425-1459. 
Table 1:

\begin{tabular}{lrrrrr}
\hline \hline & Mean & Std. Deviation & Maximum & Minimum & No. of Obs. \\
$I_{t}$ & 17.09 & 41.74 & 570.82 & 0.00 & 1485 \\
$B_{t}$ & 12.92 & 39.63 & 496.49 & 0.00 & 1485 \\
$K_{t}$ & 103.95 & 190.93 & 1023.64 & 0.39 & 89 \\
\hline \hline
\end{tabular}

Table 2: Parameter Estimates and Asymptotic Standard Errors

\begin{tabular}{|c|c|c|c|c|c|c|c|c|}
\hline$\Theta$ & (1) & $(2)$ & (3) & (4) & $(5)$ & (6) & $(7)$ & $(8)$ \\
\hline$\alpha$ & $\begin{array}{c}0.53401 \\
(0.1359)\end{array}$ & \multicolumn{2}{|c|}{0.53401} & $\begin{array}{l}0.53151 \\
(0.0210)\end{array}$ & \multicolumn{2}{|c|}{0.53151} & \multicolumn{2}{|c|}{0.600} \\
\hline$\rho$ & $\begin{array}{l}0.06247 \\
(0.0251)\end{array}$ & \multicolumn{2}{|c|}{0.06247} & $\begin{array}{c}0.07249 \\
(0.0082)\end{array}$ & \multicolumn{2}{|c|}{0.07249} & \multicolumn{2}{|c|}{0.040} \\
\hline$\delta$ & $\begin{array}{l}0.08695 \\
(0.0292)\end{array}$ & \multicolumn{2}{|c|}{0.08695} & $\begin{array}{l}0.09248 \\
(0.0106)\end{array}$ & \multicolumn{2}{|c|}{0.09248} & \multicolumn{2}{|c|}{0.070} \\
\hline$\gamma$ & $\begin{array}{l}0.93478 \\
(0.0116)\end{array}$ & $\begin{array}{l}0.93547 \\
(0.1109)\end{array}$ & $\begin{array}{l}0.93526 \\
(0.0688)\end{array}$ & $\begin{array}{c}0.919608 \\
(0.1674)\end{array}$ & $\begin{array}{l}0.91737 \\
(0.1641)\end{array}$ & $\begin{array}{l}0.91732 \\
(0.1642)\end{array}$ & $\begin{array}{l}0.82101 \\
(0.0934)\end{array}$ & $\begin{array}{l}0.82138 \\
(0.0344)\end{array}$ \\
\hline$\mu$ & $\begin{array}{l}0.33164 \\
(0.0740)\end{array}$ & $\begin{array}{l}0.28189 \\
(0.0267)\end{array}$ & $\begin{array}{c}0.281692 \\
(0.0237)\end{array}$ & $\begin{array}{c}0.38441 \\
(0.1391)\end{array}$ & $\begin{array}{c}0.45075 \\
(0.01268)\end{array}$ & $\begin{array}{l}0.45129 \\
(0.0186)\end{array}$ & $\begin{array}{l}0.49428 \\
(0.0190)\end{array}$ & $\begin{array}{c}0.49469 \\
(0.0521)\end{array}$ \\
\hline$\sigma_{\epsilon}$ & $\begin{array}{l}0.21345 \\
(0.0169)\end{array}$ & $\begin{array}{l}0.16979 \\
(0.0191)\end{array}$ & $\begin{array}{l}0.16981 \\
(0.0234)\end{array}$ & $\begin{array}{c}0.30000 \\
(0.0953)\end{array}$ & $\begin{array}{l}0.30065 \\
(0.0623)\end{array}$ & $\begin{array}{l}0.30004 \\
(0.0102)\end{array}$ & $\begin{array}{l}0.33366 \\
(0.0059)\end{array}$ & $\begin{array}{c}0.33294 \\
(0.0075)\end{array}$ \\
\hline$\sigma_{K}$ & $\begin{array}{c}341.04015 \\
(47.6622)\end{array}$ & $\begin{array}{c}302.94361 \\
(52.2031)\end{array}$ & $\begin{array}{c}331.73238 \\
(38.5239)\end{array}$ & & 15.00000 & & $\begin{array}{l}255.52567 \\
(54.60188)\end{array}$ & 15.00000 \\
\hline$\sigma_{B}$ & $\begin{array}{c}11.16525 \\
(0.6136)\end{array}$ & $\begin{array}{l}1.82048 \\
(0.1627)\end{array}$ & $\begin{array}{c}11.01284 \\
(0.5150)\end{array}$ & $\begin{array}{l}12.71158 \\
(0.2734)\end{array}$ & $\begin{array}{c}2.79773 \\
(0.09692)\end{array}$ & $\begin{array}{c}7.36763 \\
(0.13147)\end{array}$ & $\begin{array}{l}2.09673 \\
(0.1419)\end{array}$ & $\begin{array}{l}2.07875 \\
(0.0939)\end{array}$ \\
\hline$s$ & 0.00000 & $\begin{array}{l}0.73140 \\
(0.0348)\end{array}$ & 1.00000 & 0.00000 & $\begin{array}{l}0.73234 \\
(0.0127) \\
\end{array}$ & 1.00000 & $\begin{array}{l}0.71314 \\
(0.0450)\end{array}$ & $\begin{array}{l}0.34366 \\
(0.0294) \\
\end{array}$ \\
\hline $\begin{array}{c}\ln \mathcal{L} \\
L R_{s=0} \\
L R_{s=1}\end{array}$ & -1554.156 & $\begin{array}{c}-941.477 \\
1225.36 \\
1273.66\end{array}$ & -1578.309 & -4239.839 & $\begin{array}{c}-2213.572 \\
4052.53 \\
2045.97\end{array}$ & -3236.559 & -1315.680 & -6619.876 \\
\hline Obs & & & & & & & & \\
\hline
\end{tabular}


Table 3: $\chi^{2}$ Tests

\begin{tabular}{ccc}
\hline \hline Year & \multicolumn{2}{c}{$\chi^{2}$ Statistic } \\
& Capital & Debt \\
\hline \hline 1976 & 0.00 & 0.00 \\
1977 & 300.00 & 14.83 \\
1978 & 159.14 & 8.81 \\
1979 & 101.82 & 7.96 \\
1980 & 39.01 & 11.52 \\
1981 & 31.63 & 14.00 \\
1982 & 13.10 & 11.07 \\
1983 & 8.79 & 6.85 \\
1984 & 17.38 & 14.36 \\
1985 & 9.81 & 9.39 \\
1986 & 7.15 & 2.34 \\
1987 & 2.35 & 6.59 \\
1988 & 3.91 & 6.19 \\
1989 & 3.23 & 4.56 \\
1990 & 2.60 & 2.67 \\
1991 & 1.02 & 4.36 \\
1992 & 0.98 & 5.19 \\
1993 & 1.42 & 5.23 \\
1994 & 0.88 & 10.00 \\
1995 & 5.48 & 4.25 \\
\hline \hline
\end{tabular}


Table 4: Relaxing the Dividend Constraint

\begin{tabular}{l|r|r|r}
\hline \hline & $s=0$ & $s=0.73$ & $s=1$ \\
\hline Average Capital Stock & 166.05 & 181.42 & 192.69 \\
All Firms & 157.92 & 173.70 & 185.46 \\
Small Firms & 194.89 & 201.32 & 205.36 \\
Large Firms & & & \\
Average Capital Stock & 5 th Year & & \\
All firms & 164.28 & 184.46 & 198.78 \\
Small Firms & 162.05 & 182.45 & 194.25 \\
Large Firms & 198.81 & 214.33 & 216.98 \\
& & & \\
Average Capital Stock & 10 th Year & & \\
All Firms & 160.38 & 172.10 & 178.07 \\
Small Firms & 158.47 & 171.00 & 178.05 \\
Large Firms & 180.83 & 179.54 & 178.25 \\
& & & \\
Average Capital Stock & 15 th Year & & \\
All Firms & 171.65 & 173.08 & 173.08 \\
Small Firms & 168.58 & 171.05 & 171.05 \\
Large Firms & 174.01 & 174.01 & 174.83 \\
\hline \hline
\end{tabular}

Note: All data is in millions of dollars. 
Figure 1: Policy Rule for $K^{\prime}$

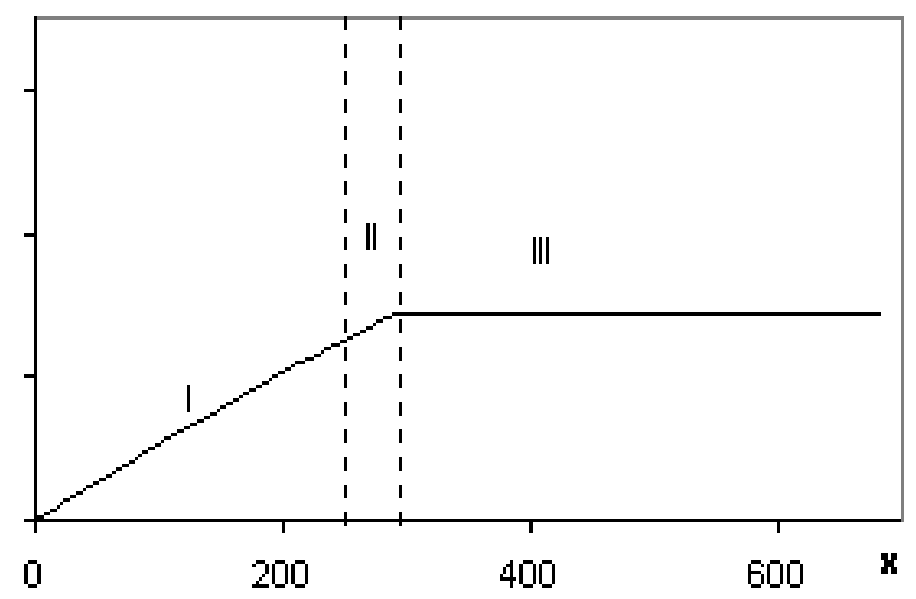

Figure 2: Policy Rule for $B^{\prime}$

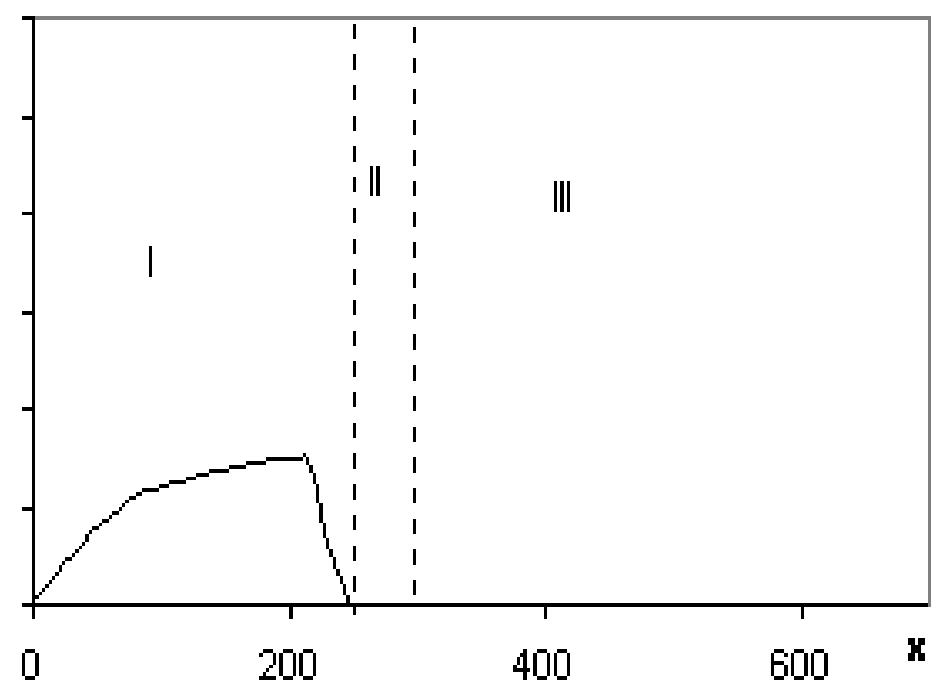


Figure 3: Slope of the Value Function

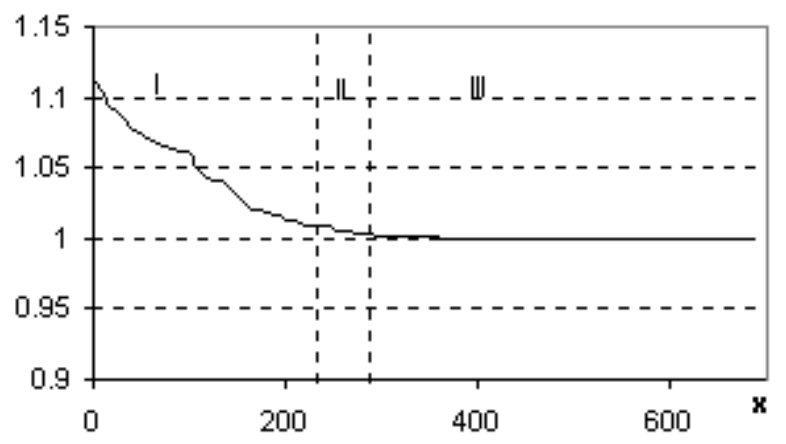

Figure 4: Dividends

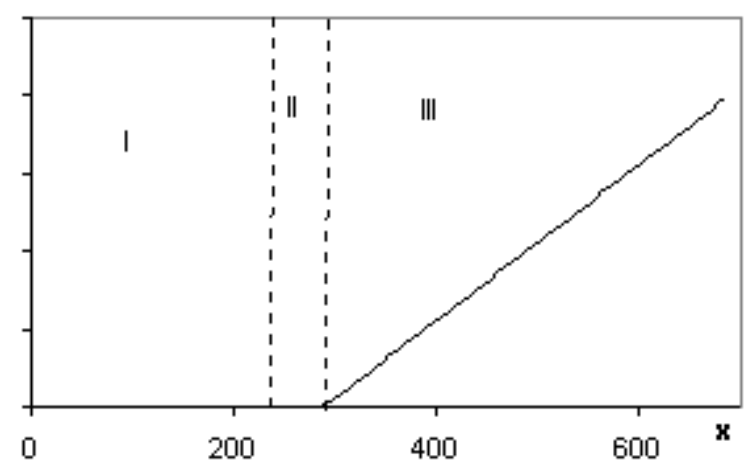


Figure 5: Relaxing the Dividend Constraint.Policy Rule for $K^{\prime}$

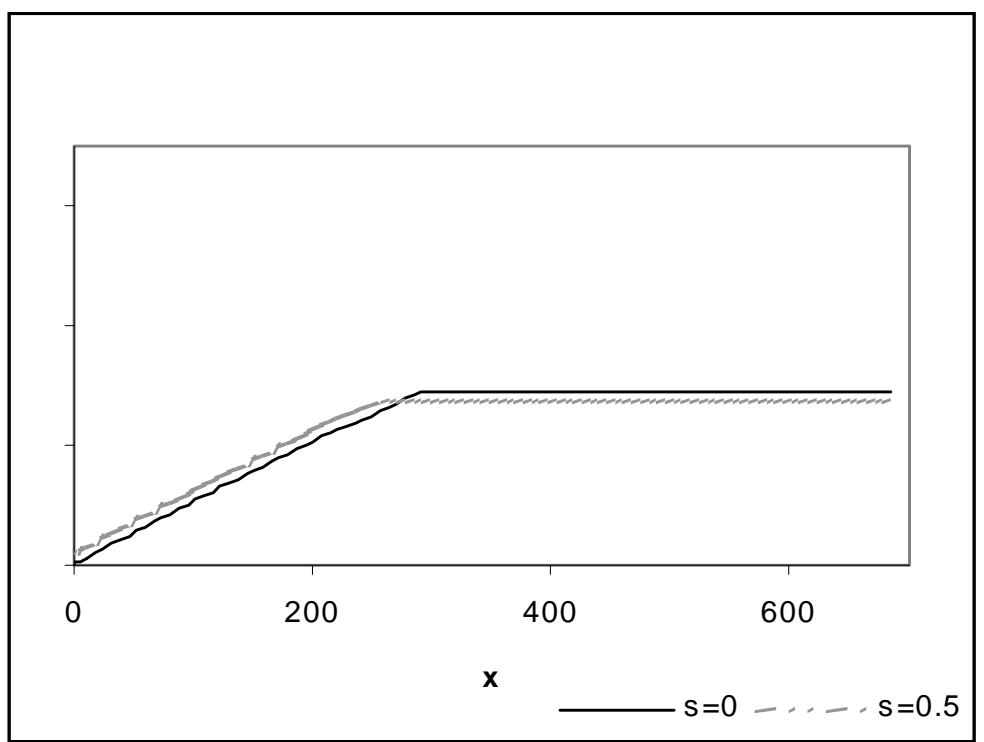

Figure 6: Relaxing the Dividend Constraint.Policy Rule for $B^{\prime}$

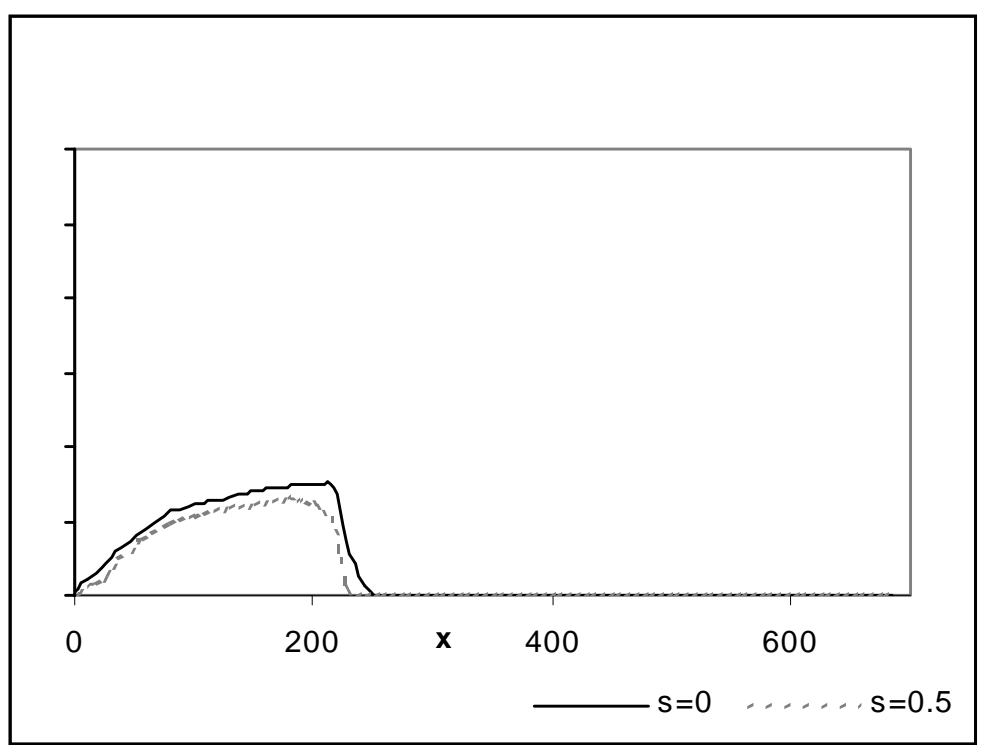


Figure 7: Actual and Model Predicted Capital

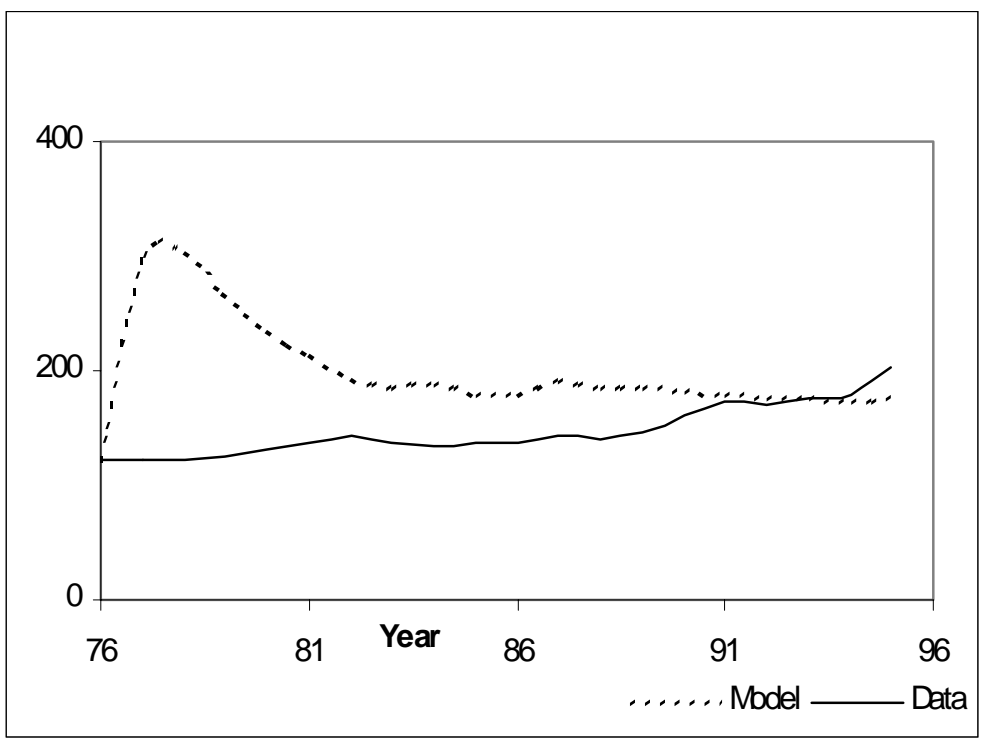

Figure 8: Actual and Model Predicted Debt

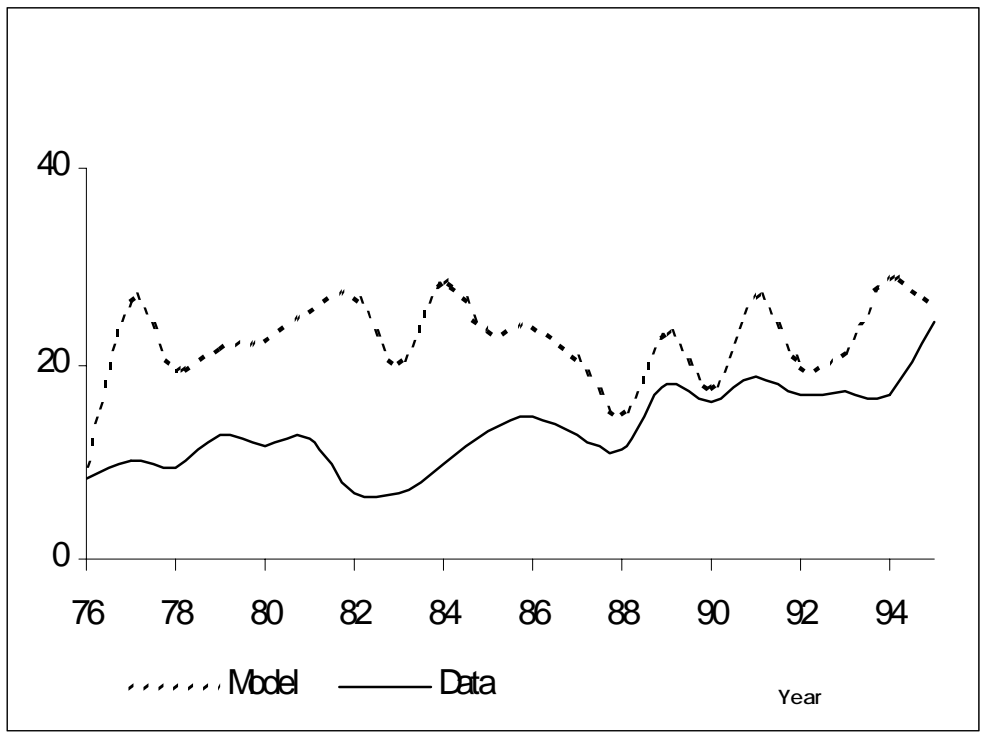


Figure 9: Average Capital Stock: All Firms

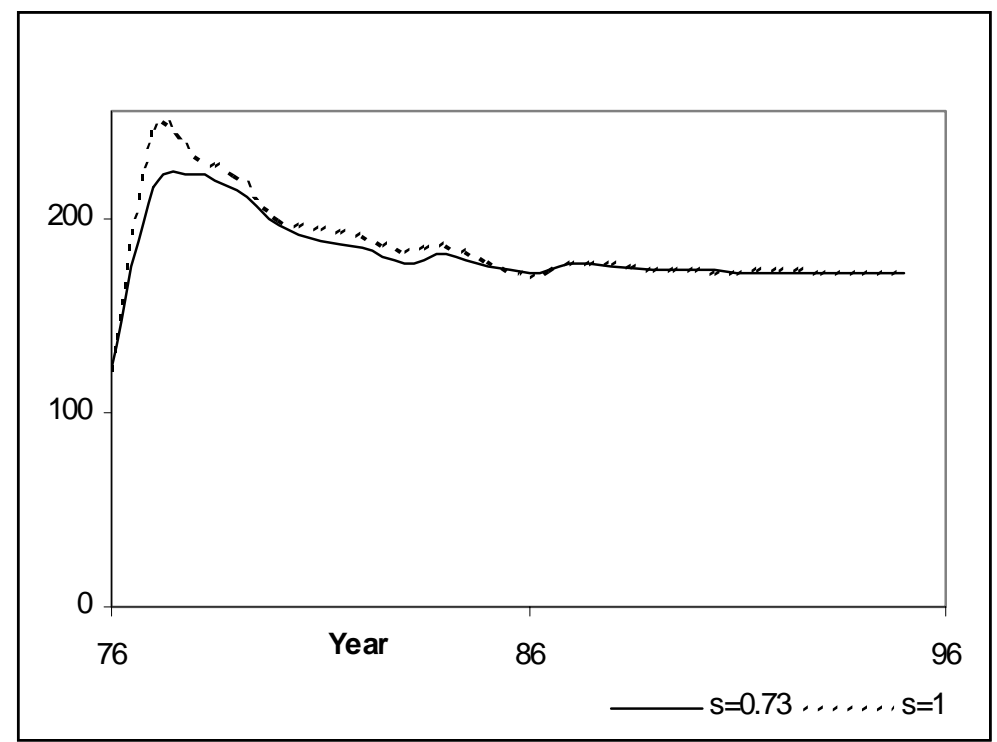

Figure 10: Average Capital Stock: Small Firms

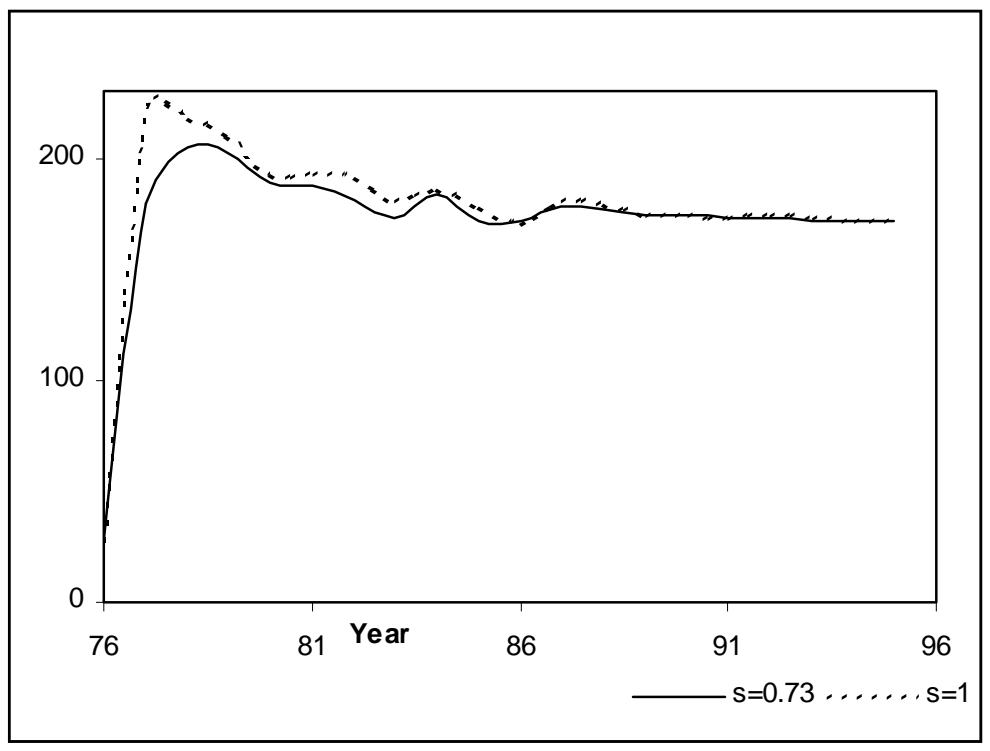


Figure 11: Average Capital Stock: Large Firms

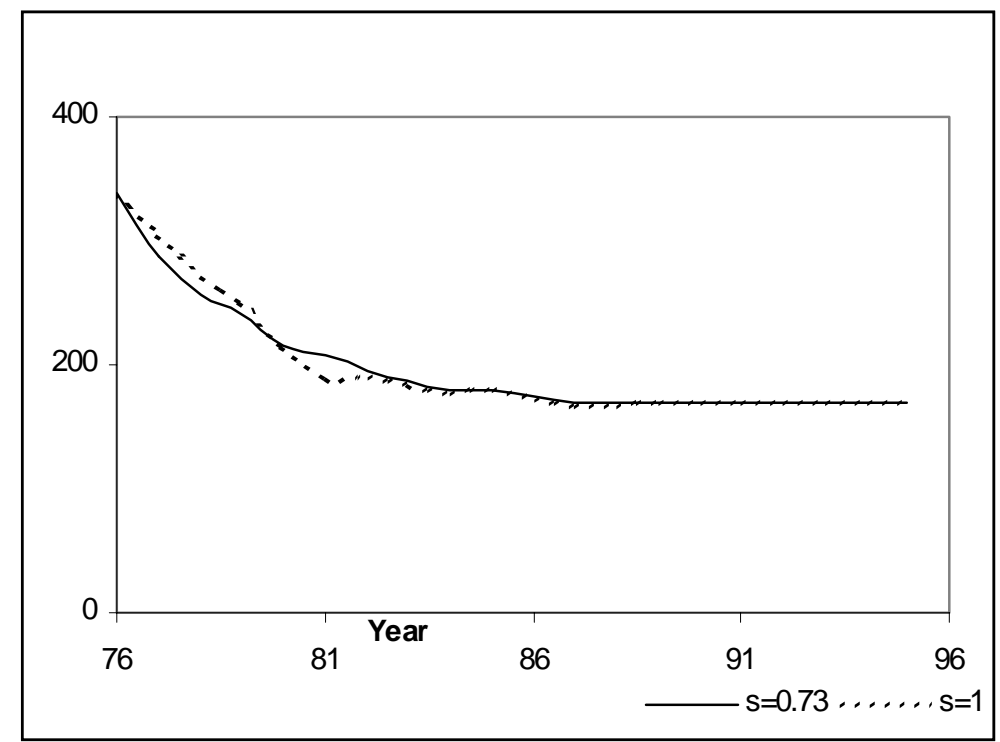

Figure 12: Response of Capital to a 1\% Transitory Increase in Interest Rates

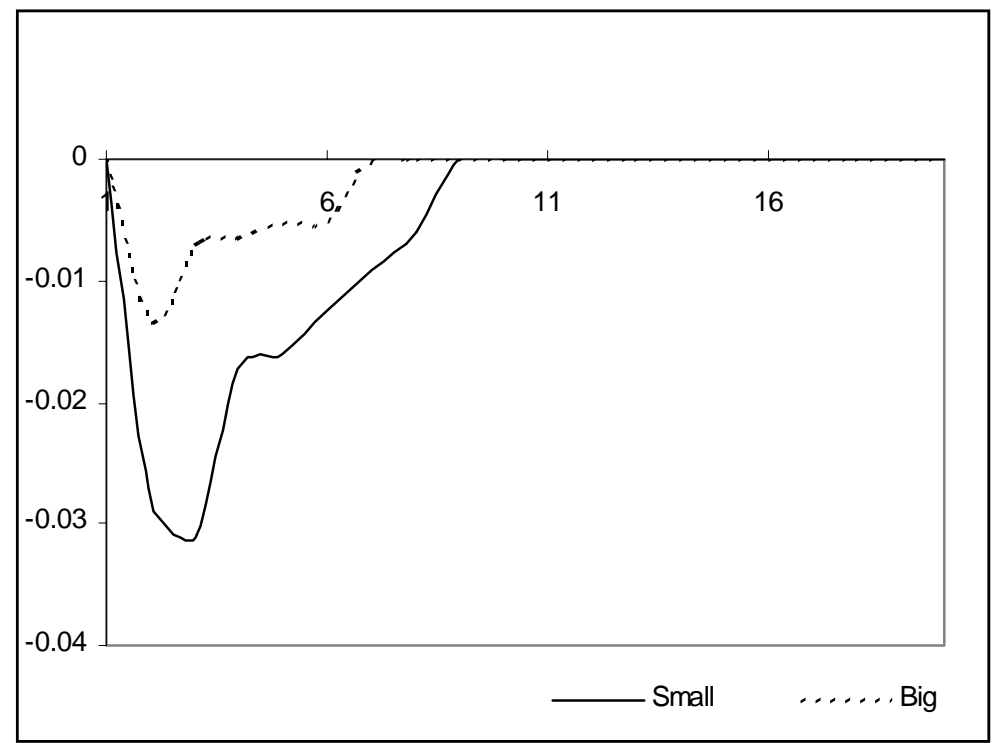

